\title{
Pleiotropic Cellular Functions of PARP1 in Longevity and Aging: Genome Maintenance Meets Inflammation
}

\author{
Aswin Mangerich and Alexander Bürkle \\ Molecular Toxicology Group, Department of Biology, University of Konstanz, 78457 Konstanz, Germany \\ Correspondence should be addressed to Aswin Mangerich, aswin.mangerich@uni-konstanz.de \\ and Alexander Bürkle, alexander.buerkle@uni-konstanz.de
}

Received 1 June 2012; Accepted 25 July 2012

Academic Editor: Paula Ludovico

Copyright (C) 2012 A. Mangerich and A. Bürkle. This is an open access article distributed under the Creative Commons Attribution License, which permits unrestricted use, distribution, and reproduction in any medium, provided the original work is properly cited.

\begin{abstract}
Aging is a multifactorial process that depends on diverse molecular and cellular mechanisms, such as genome maintenance and inflammation. The nuclear enzyme poly(ADP-ribose) polymerase 1 (PARP1), which catalyzes the synthesis of the biopolymer poly(ADP-ribose), exhibits an essential role in both processes. On the one hand, PARP1 serves as a genomic caretaker as it participates in chromatin remodelling, DNA repair, telomere maintenance, resolution of replicative stress, and cell cycle control. On the other hand, PARP1 acts as a mediator of inflammation due to its function as a regulator of NF- $\kappa \mathrm{B}$ and other transcription factors and its potential to induce cell death. Consequently, PARP1 represents an interesting player in several aging mechanisms and is discussed as a longevity assurance factor on the one hand and an aging-promoting factor on the other hand. Here, we review the molecular mechanisms underlying the various roles of PARP1 in longevity and aging with special emphasis on cellular studies and we briefly discuss the results in the context of in vivo studies in mice and humans.
\end{abstract}

\section{Genomic Stability, Inflammation, and Aging}

Aging has been defined as a progressive postmaturational decline in physiological capacity, accompanied by an increased susceptibility to disease and an increased mortality risk. Mechanisms to maintain genomic stability are thought to counteract the aging process, whereas inflammation is considered a driving force of human aging [1].

A large body of evidence supports the theory that genomic instability acts as a causative factor in the aging process, which is evident from the fact that most mouse models of premature aging as well as human progeria syndromes are related to defects in mechanisms of genomic maintenance [2]. This may be attributed to the fact that DNA serves as a blueprint of all cellular RNAs and proteins. Any acquired change in its sequence, which may arise from molecular damage, is permanent and thus may have irreversible consequences. For this reason nature invested in a sophisticated network of various mechanisms (i) to maintain genome integrity, such as DNA repair and cell cycle control, and (ii) to withdraw heavily damaged cells from the body, such as apoptosis and cellular senescence. However, even if these mechanisms may be very efficient they cannot cope with all the insults induced in the genome, leading to a gradual accumulation of DNA damage and mutations, thus contributing to organismic aging [2].

On the other hand, a direct relationship exists between physiological aging and increasing incidence of chronic inflammatory diseases. In its acute form, inflammation acts as a protective mechanism in response to pathogen invasion or tissue damage and helps to restore physiological integrity and function. However, in its chronic form, inflammation can exert detrimental effects on the cellular as well as the organismic level. Chronically inflamed tissue is characterized by infiltration of immune cells, neovascularization, fibrosis, and often tissue damage and necrosis [3]. The innate immune system, especially the mononuclear phagocyte system, is the most important mediator of chronic inflammation. Monocytes originate from the myeloid hematopoietic cell lineage in bone marrow. In the blood stream, monocytes are recruited by specific stimuli into different tissues, where they differentiate into phagocytic 
macrophages. Macrophages participate in the killing of invading microorganisms and emerging tumor cells through the production of reactive oxygen or nitrogen species (ROS and RNS). In addition, macrophages secrete cytokines, which play a key role in the regulation of multiple immune functions, especially inflammatory responses [3]. During aging, the continuous pressure on the immune system caused by repeated antigen stimulation, such as infections, food antigens, allergens, and self antigens, leads to an increase in activated cells and secretion of proinflammatory cytokines, such as TNF $\alpha$ [4]. These circulating proinflammatory factors may keep the immune system in a state of chronic lowlevel activation, a phenomenon described as "inflammaging" $[5,6]$. Eventually, this causes "immunosenescence," that is, an age-related decline in the capacity of adaptive immunity, consisting of more specific responses carried out by B and $\mathrm{T}$ cells [7]. Thus, with advanced age, the immune system undergoes a gradual remodeling in the attempt to reestablish a new balance that assures survival, however, favoring the development of chronic inflammatory conditions $[5,6,8,9]$.

DNA damage and inflammation are inevitably linked by the production of reactive chemical species, such as ROS and RNS. Cellular ROS and RNS production occurs constantly under physiological as well as pathophysiological conditions as a consequence of electron leakage of the mitochondrial electron transport chain and via enzymes such as NADPH oxidase, nitric oxide synthases, and xanthine oxidase. The "free radical theory of aging" posits that aging and its related diseases are the net consequence of free radicalinduced damage and the inability to counterbalance these changes by antioxidative defenses and sufficient DNA repair [10]. Chronic inflammation results in the generation of a broad spectrum of ROS and RNS by activated macrophages and neutrophils, which damage cellular macromolecules including DNA [11, 12]. Conversely, the generation of ROS and RNS activates redox sensitive transcription factors, such as NF- $\kappa \mathrm{B}$, resulting in the generation of proinflammatory molecules. Moreover, DNA damage can induce cellular senescence, a tumor suppressive mechanism that is also associated with aging, leading to the secretion of inflammatory cytokines, a paracrine effect known as senescence-associated secretory phenotype (SASP) [5, 13]. Altogether, this can trigger a positive feedback loop that amplifies the processes of inflammation, damage, and destruction in target cells and organs, leading to an organismic decline and death over time. For example, chronic inflammation has been associated with an age-related decline in the function of hematopoietic and mesenchymal stem cells $[14,15]$ and has been implicated as a mediator of almost all of the aging-associated diseases, such as vascular diseases, diabetes, neurodegenerative diseases, and cancer $[3,5,6,9]$.

As discussed below, the nuclear enzyme PARP1 represents a factor that works at the interface between genomic maintenance and inflammation. Therefore, PARP1 may act in an antagonistic pleiotropic way, that is, functioning as a longevity assurance factor at younger age or in physiological conditions and as an aging-promoting factor at older age or in pathophysiological conditions. In this paper, we will discuss the numerous cellular functions of PARP1 in the context of mechanisms of longevity and aging and will put this into an organismic perspective by briefly summarizing in vivo studies in mice and humans.

\section{PARP1 and Poly(ADP-ribosyl)ation}

Poly(ADP-ribosyl)ation is a posttranslational modification of proteins that occurs in most eukaryotic organisms. The reaction is carried out by enzymes of the family of poly(ADPribose) polymerases (PARPs) by using $\mathrm{NAD}^{+}$as a substrate to synthesize the linear or branched biopolymer poly(ADPribose) (PAR), which consist of up to 200 ADP-ribose subunits (Figure 1) [16]. PARP activation leads to covalent modification of various proteins with PAR including PARPs themselves, as some of them catalyze their automodification. Covalent linkage is mediated either through attachment on glutamate, aspartate, or lysine residues of the acceptor proteins [16]. Apart from covalent modification, some proteins can also bind preexisting ADP-ribose chains in a noncovalent fashion, and this binding is mediated via at least three different PAR binding motifs. Those include (i) a 20 amino acid motif, (ii) distinct macrodomains, and (iii) a PAR-binding zinc finger, all of which fulfill diverse cellular functions [17-22]. Whereas the PAR-binding macrodomains and zinc fingers are present in a limited number of human proteins $(<50)$, the 20 -aa motif has been identified in several hundred human protein sequences $[17,18]$. This weakly conserved motif consists of (i) a cluster rich in basic amino acids and (ii) a pattern of hydrophobic amino acids interspersed with basic residues [17, 18]. Most of the putative PAR-binding proteins identified are involved in a wide spectrum of cellular mechanisms such as genomic maintenance, chromatin remodeling, transcription, replication, RNA metabolism, inflammation, cell cycle control, and cell death [18]. In general, poly(ADP-ribosyl)ation modulates target protein function by modifying enzymatic activities or interactions with other macromolecules such as DNA, RNA, or proteins [23].

Importantly, the cellular existence of PAR is transient, since the polymer is rapidly hydrolyzed by PARPs catabolic counterpart, poly(ADP-ribose) glycohydrolase (PARG). PARG possesses both exo- and endoglycosidic activities and is encoded by a single gene giving rise to at least five different splice variants with distinct subcellular localizations [24-26]. In addition, a second enzyme was identified with weak PARG activity, that is, ADP-ribose-arginine protein hydrolase 3 (ARH3), with evidence that this enzyme is associated with PAR degradation in mitochondria $[27,28]$.

The PARP gene family consists of 17 homologues in the human genome [16]. PARP1 is the founding member of the gene family. It exhibits key roles in the regulation of nuclear and cellular functions and can be activated either by DNA damage, posttranslational protein modifications, or potentially by direct protein-protein interactions [29]. The strongest stimulation of PARP1 activity is mediated by its binding to DNA strand breaks which induces its catalytic activation as a monomer or dimer by several hundredfold [30-33]. Under these conditions, PARP1 accounts for $>75 \%$ of the overall cellular poly(ADP-ribosyl)ation capacity 


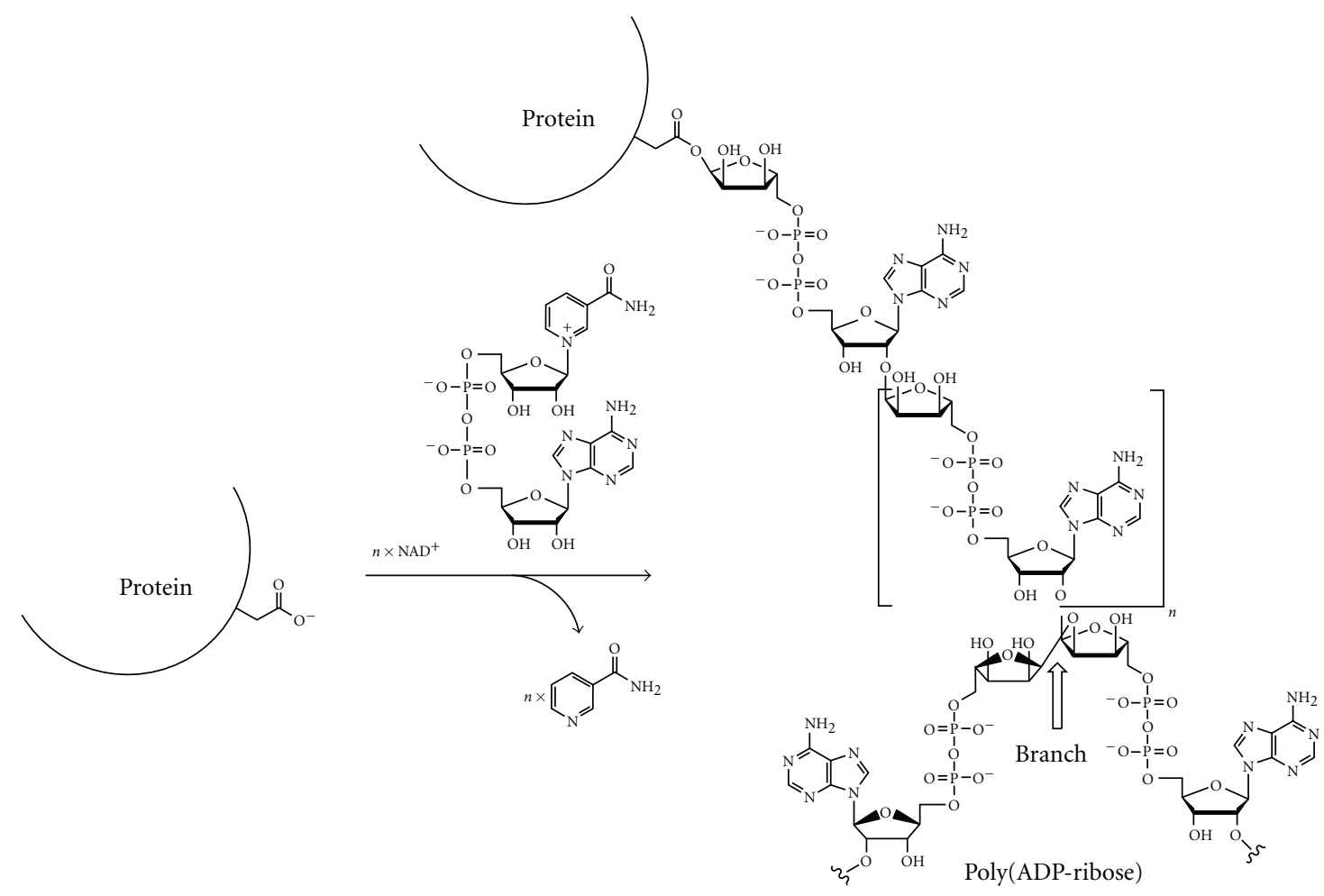

Figure 1: Poly(ADP-ribosyl)ation. PARPs cleave the glycosidic bond of $\mathrm{NAD}^{+}$between nicotinamide and ribose followed by the covalent modification of acceptor proteins with an ADP-ribosyl unit. PARPs also catalyze an adduct elongation, giving rise to linear polymers with chain lengths of up to $200 \mathrm{ADP}$-ribosyl units, characterized by their unique ribose $\left(1^{\prime \prime} \rightarrow 2^{\prime}\right)$ ribose phosphate-phosphate backbone. At least some of the PARP family members also catalyze a branching reaction by creating ribose $\left(1^{\prime \prime \prime} \rightarrow 2^{\prime \prime}\right)$ ribose linkages.

$[34,35]$. Apart from direct DNA damage-dependent PARP1 activation, its activity is also regulated by posttranslational modifications such as phosphorylation, acetylation, and sumoylation [36-40]. Moreover, PARP1 activity is subject to regulation by direct protein-protein interactions [41-43].

Three nonexclusive mechanisms of the cellular functions of PARP1 can be distinguished: (i) functions that rely on the enzymatic activity of PARP1 and the subsequent covalent modification or noncovalent interaction of nuclear proteins with PAR; (ii) direct interactions of proteins with PARP1 via protein-protein interaction, for example, via the BRCT domain; (iii) intervention in the cellular $\mathrm{NAD}^{+}$metabolism by excessive PARP1 stimulation and potential signaling functions of free PAR or its derivatives. The consequences of these actions with regard to modulation of genomic maintenance, chromatin structure, inflammation, and cell death are discussed below.

\section{PARP1 in Genomic Maintenance}

It is estimated that thousands of DNA damage lesions occur in a mammalian cell per day, all of which need to be repaired to ensure genomic stability and longevity. In mammals, at least six major DNA repair pathways exist, that is, $\mathrm{O}^{6}$ methyl guanine methyltransferase (MGMT), base excision repair (BER), nucleotide excision repair (NER), mismatch repair (MMR), and DNA double-strand break (DSB) repair including the subpathways homologous recombination (HR) and nonhomologous end-joining (NHEJ) [2].

Except for the MGMT and MMR pathways, there is evidence that PARP1 is involved in all of these repair mechanisms, and therefore, PARP1 is considered a general caretaker of genomic stability [29]. Of note, the recruitment of PARP1 to sites of DNA damage and the subsequent production of PAR can occur within seconds and is one of the fastest DNA damage responses [44, 45]. Apart from this direct involvement in several DNA repair mechanisms, PARP1 participates in genomic maintenance through its role as a regulator of chromatin structure and cell cycle regulation (Figure 2).

Several cellular studies support a role of PARP1 as a general cell survival factor upon genotoxic stimuli: transdominant inhibition of PARP1 by overexpression of its DNA binding domain potentiates cytotoxicity upon treatment of cells with alkylating agents and ionizing radiation [46]. Moreover, PARP1-deficient cells exhibit an enhanced sensitivity to alkylating agents $[47,48]$ and show increased frequencies of sister chromatid exchanges, both under basal conditions and upon treatment with alkylating agents $[49,50]$. Consistent with this, overexpression studies demonstrated that PARP1 acts as a negative regulator of alkylation-induced sister chromatid exchange [51], and ex vivo supplementation of human PBMC with the $\mathrm{NAD}^{+}$precursor nicotinic acid enhances cellular poly(ADP-ribosyl)ation and improves cell viability upon induction of genotoxic stress [52]. 


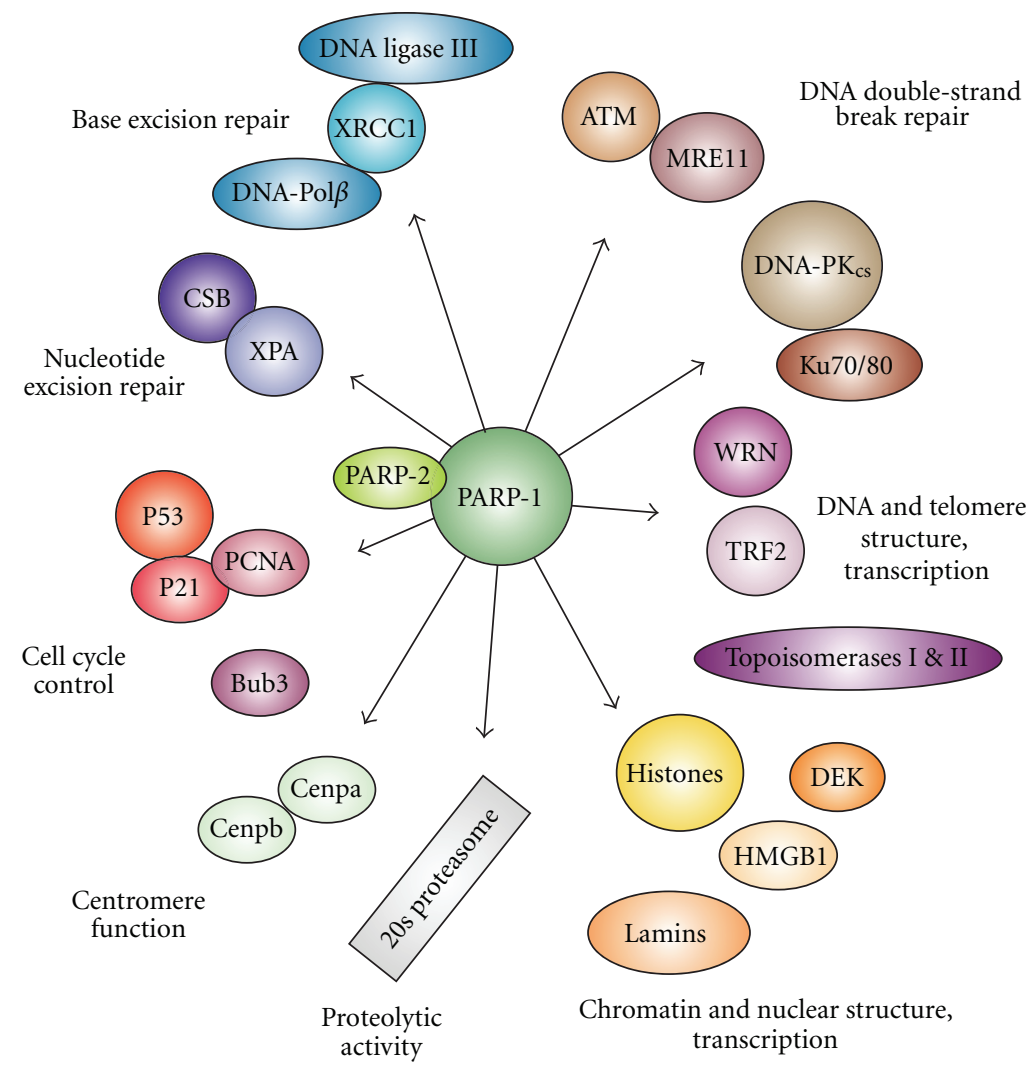

FIGURE 2: PARP1, some interaction partners, and their role in genomic maintenance. ATM indicates ataxia telangiectasia mutated; Bub3, budding uninhibited by benzimidazoles 2 ; Cenpa/b, centromeric protein a/b; CSB, Cockayne syndrome type B; DEK, DEK oncogene; DNA$\operatorname{Pol} \beta$, DNA polymerase $\beta$; DNA-PK $\mathrm{CS}_{\mathrm{C}}$, DNA-activated protein kinase catalytic subunit; HMGB1, high mobility group box 1 ; Ku70/80, Ku antigens $70 / 80 \mathrm{kDa}$ subunit; MRE11, meiotic recombination 11; p21, cyclin-dependent kinase inhibitor 1A; p53, tumor suppressor protein p53; PCNA, proliferating cell nuclear antigen; TRF2, telomeric repeat binding factor 2; WRN, Werner syndrome protein; XRCC1, X-ray repair complementing defective in Chinese hamster 1; XPA, xeroderma pigmentosum complementation group A.

3.1. PARP1 and Chromatin Regulation. Chromatin is a complex of DNA and proteins with a dynamic structure and is involved in replication, transcription, and other fundamental cellular processes. Structural and functional alterations of chromatin are widely associated with aging from yeast to mammals [53]. The molecular mechanisms leading to chromatin disturbances in aging are largely unknown, but may be related to accumulation of unrepaired DNA damage. On the other hand, alterations in chromatin structure increase the susceptibility to DNA damage, suggesting the presence of a positive feedback mechanism of DNA damage leading to chromatin rearrangements which, in turn, sensitizes DNA as a substrate for further damage. Moreover, there is evidence that chromatin defects lead to alterations in transcriptional programs thereby contributing to the aging process [53].

PARP1 acts as a structural and regulatory component of chromatin, both in undamaged cells and upon genotoxic stress. It may either regulate chromatin structure directly by poly(ADP-ribosyl)ation of chromatin components, or indirectly by controlling the recruitment of chromatin remodeling factors [54]. Many PAR acceptor and binding proteins contribute to chromatin and nuclear architecture such as histones, lamins, high-mobility group (HMG) proteins, heterochromatin protein 1 (HP1), and the DEK protein
[54-59]. It was proposed that PARP1 induces a histoneshuttling mechanism, based on findings that poly(ADPribosyl)ation of polynucleosomes causes relaxation of chromatin structure and that activity of PARG degrades PAR from modified histones [60-63]. According to this model, DNA-bound histones dissociate from DNA upon poly(ADPribosyl)ation, causing an open chromatin structure and guiding repair factors to sites of DNA damage. Upon degradation of PAR by PARG, DNA reassociates with histones, thereby restoring the condensed chromatin structure. Moreover, upon DNA damage, PARP1 activation leads to the recruitment of the histone variant macroH2A1.1 to the site of the damage, which transiently causes chromatin rearrangements and dynamically modulates the DNA damage response [22]. Kim et al. reported that PARP1 itself can function as a component of chromatin [64], that is, histone $\mathrm{H} 1$ and PARP1 bind in a competitive and mutually exclusive manner to nucleosomes in vitro. Thereby, PARP1 promotes the local compaction of chromatin into higher order structures, which are associated with transcriptional repression. The authors suggested that PARP1 modulates the chromatin architecture and gene transcription through its intrinsic enzymatic activity in a DNA damage-independent manner; that is, PARP1 activation and automodification 
trigger its release from chromatin, thereby facilitating chromatin decondensation and gene transcription by RNA polymerase II. Subsequent cellular studies demonstrated that PARP1 could replace histone H1 at RNA polymerase II-transcribed promoters, which was associated with actively transcribed genes [65].

Apart from a functional interplay between PARP1 with histones, an interesting physical and functional interaction exists between PARP1 and DEK. The DEK protein is a major nonhistone chromatin component with functions in DNA metabolism and repair on a cellular, and carcinogenesis and autoimmunity on an organismic level. DEK is often found to be upregulated in tumor tissue, and high levels of DEK favor cell immortalization by inhibiting senescence and apoptosis. Consistently, DEK deficient cells are prone to induction of senescence in the response to genotoxic stress [66]. We and others have shown that PARP1 poly(ADPribosyl)ates DEK. Moreover, DEK interacts with PAR in a non-covalent manner which regulates its DNA binding affinity and multimerization with possible implications in response to genotoxic stress and gene transcription. In terms of gene transcription, DEK is released from chromatin upon poly(ADP-ribosyl)ation to permit transcriptional initiation $[56,59,67]$. Whether DEK itself or its interplay with PARP1 has a direct role in aging mechanisms remains to be clarified.

PARP1 activation is also necessary for the exchange of histone $\mathrm{H} 1$ with high-mobility group B (HMGB) proteins, which are non-histone chromatin-associated proteins that bend DNA and recruit transcription factors to their DNA targets [68]. Interestingly, during inflammation, HMGB1 can be secreted by activated cells, where it inhibits phagocytic uptake of dying cells by macrophages. HMGB1 secreted upon specific stimuli, that is, TLR4 stimulation is highly poly(ADP-ribosyl)ated, which enhances the inhibitory effect of HMGB1 on macrophage-dependent phagocytosis. This indicates a regulatory role of PAR in such inflammatory mechanisms with potential implications in mechanisms of aging as discussed below [69].

Importantly, not only structural components of the chromatin are regulated by poly(ADP-ribosyl)ation, PAR also serves as an important factor in the regulation of chromatin remodeling factors, such as ALC1 and NURD [21, 70-72]. For example, the recruitment of the NURD chromatin remodeling complex to sites of DNA lesions depends on the synthesis of PAR. Interestingly, this complex was identified as an important modulator of aging-associated chromatin defects, and loss of several NURD components and function was evident during human premature aging [73].

The role of PARP1 in gene transcription and chromatin remodeling was impressively demonstrated in a Drosophila study [74]. The authors revealed that PARP1 is crucial for puff formation in giant polytene chromosomes. Puff formation arises from local relaxation of the chromatin structure and is associated with actively transcribed regions [74]. Ju et al. provided interesting mechanistic evidence linking PARP1-dependent initiation of transcription and its function in DNA binding [68]. According to this work, PARP1 acts in concert with another binding partner, that is, topoisomerase II. Topoisomerase II introduces a transient double strand break at the promoter, which leads to PARP1 binding and activation. The subsequent rapid but transient poly(ADP-ribosyl)ation triggers chromatin relaxation and initiation of transcription.

Together, these findings suggest a functional interplay of PARP1 with chromatin components and associated remodeling factors, implying an active role of PARP1 in chromatin function and transcriptional regulation during the aging process. Gene profiling data support such a hypothesis, since PARP1 deficiency alters expression of genes involved in cell cycle progression, DNA replication, oxidative stress, cancer initiation, and aging [75, 76]. The detailed spatial and temporal characteristics of these mechanisms, however, remain to be determined.

3.2. PARP1 in DNA Repair. As discussed above, a substantial body of evidence demonstrates a causative role of DNA repair and genome maintenance mechanisms in mammalian longevity.

Base excision repair (BER) is the major DNA repair pathway that acts on damage that occurs during cellular metabolism including damage from ROS, methylation, deamination, and hydroxylation. The levels of many of these lesions increase with age including the well-studied lesion 8-oxoguanine. Moreover, BER activity decreases with age in multiple tissues [77]. The core BER reaction is initiated by a DNA single-strand break (SSB) upon excision of the damaged bases by DNA glycosylases [78]. PARP1 detects such SSB via its second zinc finger (ZFII), thus triggering its enzymatic activation $[79,80]$. Moreover, PARP1 physically cooperates with 8-oxoguanine-DNA glycosylase, which further stimulates PARP1 activity [81]. Importantly, the recruitment of the BER loading platform X-ray repair complementing factor 1 (XRCC1) is completely dependent on poly(ADP-ribsosyl)ation [82, 83]. Thus, PARP1 and PAR are required for the assembly and stability of XRCC1 nuclear foci after DNA damage [83]. Furthermore, XRCC1 and PARP1 interact with DNA polymerase- $\beta$ and DNA ligase III, forming a multiprotein complex consisting of the major BER factors [84-86].

The finding that PARP1-deficient cells still synthesized PAR led to the identification of an additional nuclear PARP, that is, PARP2, which is also activated upon genotoxic stimuli $[34,35]$. PARP1 and PARP2 homo- and heterodimerize and work at least partially in a redundant fashion, since only double-knockout mice show embryonic lethality [87, 88]. This notion is supported by the fact that PARP2 also participates in BER and interacts physically and functionally with XRCC1, DNA polymerase- $\beta$, and DNA ligase III. Recruitment studies indicate a role of PARP2 in later steps of BER repair, as proposed by the following model for spatiotemporal accumulation of BER factors: SSBs are detected by the DNA binding domain of PARP1, leading to its activation, production of PAR, and chromatin relaxation. Subsequently, additional PARP1 molecules are attracted, causing amplification of the signal. At the "point of repulsion," PARP1 then dissociates from the DNA, enabling the recruitment of the BER loading platform XRCC1, PARP2, 
and further DNA repair factors. This triggers resealing of the DNA lesion and reestablishment of genomic integrity [89].

Nucleotide excision repair is responsible for the removal of bulky helix-distorting DNA adducts, which are caused by UV irradiation and endogenous metabolites [78]. The functional role of the NER as a longevity assurance mechanism is impressively represented by the fact that patients with defects in a subset of NER proteins, that is, CSA and CSB (Cockayne syndrome) and XPB, XPD, TTDA (trichothiodystrophy), as well as corresponding mouse models, show in some tissues a strong premature aging phenotype [2]. Although the role of PARP1 in NER is not very well established, at least two NER factors, the DNA-dependent ATPase Cockayne syndrome group $\mathrm{B}(\mathrm{CSB})$ protein and the DNA lesion recognition protein xeroderma pigmentosum group A (XPA), were identified as PAR binding factors [17, 90, 91]. CSB also physically interacts with PARP1 and its ATPase activity is inhibited by poly(ADP-ribosyl)ation. Consistently, there is some evidence from cell culture studies that PARP1 is involved in NER of UV photo-damage products [92, 93].

DNA double strand breaks (DSBs) arise from ionizing radiation, free radicals, chemicals, or during replication of a SSB through collapsed replication forks. They represent the most cytotoxic form of DNA damage and, if unrepaired, they can trigger apoptosis, senescence, or genomic instability. Mammalian cells repair DSBs via two mechanisms: homologous recombination (HR) utilizes the sister chromatid or chromosome for error-free repair of the DSB, whereas nonhomologous end-joining (NHEJ) simply reattaches free DNA ends without using a template. For this reason, NHEJ is prone to microdeletions or insertions which can cause frameshift mutations [78]. Whether HR or NHJE is employed depends on the species, cell type, and cell cycle phase [94]. In both pathways, PARP1 already participates at very early stages. PARP1 and the DSB sensing complexes MRN (MRE11/Rad50/NBS1) (involved in HR) and Ku70/80 (involved in NHEJ) were shown to interact with and compete for binding at free DNA ends, with PARP1 potentially guiding these proteins to the damaged site $[44,95]$. PARP1 also physically and functionally interacts with two phosphatidyl inositol 3-like protein kinases ATM

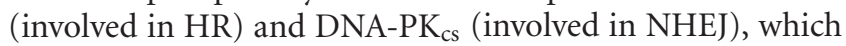
are crucial for DSB signaling [96-99]. It was suggested that PARP1 serves as a general DNA-damage-detecting molecule, which potentially mediates a switch between the NHEJ and the HR pathways [94]. Consistent with this, PARP1 functions in a NHEJ back up pathway $[95,100]$, and several reports demonstrated an antirecombinogenic activity of PARP1 [101-103]. Some information on the role of PARP1 in DSB repair was obtained from studies investigating the possible use of PARP inhibitors as anticancer drugs following the concept of synthetic lethality. According to this concept, PARP1 inhibition alone shows no cytotoxic effect on HR proficient cells, but causes cytotoxicity in HR-defective cells, for example, BRCA mutant cancer cells. This cytotoxicity is thought to be induced by accumulation of unrepaired SSBs, which are converted to DSBs by collisions with the replication machinery which cannot be repaired due to the lack of HR, ultimately triggering cell death [104]. A recent study challenged this view by presenting an alternative model based on the finding that coinactivation of NHEJ rescued the synthetic lethal effect in BRCA1-deficient cells indicating that PARP1 catalytic activity regulates NHEJ activity, thus preventing NHEJ components from binding to sites of DNA damage [105]. Yet another study reported that loss of PARP1 activity itself can inhibit HR by suppressing the expression of BRCA1 and RAD51, two key factors in HR [106]. Moreover, PARP1 is activated at stalled forks to mediate Mre11dependent replication restart by HR [107]. Another level of complexity is added by recent work demonstrating that SIRT6, a mammalian homolog of the yeast Sir2 deacetylase which functions as a longevity regulator in yeast, is recruited to sites of DSBs. There, SIRT6 appears to stimulate DSB repair via NHEJ and HR. Of note, SIRT6 interacts with PARP1 and stimulates its activity thereby enhancing DSB repair upon oxidative stress [108]. It is important to note that the results mentioned above are not necessarily mutually exclusive, but more work is necessary to define the exact molecular mechanisms by which PARP1 participates in DSB repair and which role this may have during aging.

\subsection{PARP1, Telomere Maintenance, and the WRN Protein.} Telomeres are repetitive sequences at the end of the chromosomes and function as a buffer to prevent loss of coding sequences during DNA replication. They are capped by a protein complex known as shelterin, which tightly regulates the telomeric structure by interaction with several DNA repair proteins and the telomere-elongating reverse transcriptase, telomerase. Deterioration of telomeres represents an important factor during human aging [109].

The role of PARP1 in the regulation of telomere length is well established. In vivo, a substantial loss of telomeric DNA by $30 \%$ was observed in the first generation of Parp $^{-1-}$ mice [110]. Gomez et al. reported that PARP1 is dispensable for the capping of normal telomeres, but is specifically recruited to eroded telomeres, where it might help to protect chromosomes against end-to-end fusions and genomic instability [111]. Our group demonstrated in various cell culture systems that pharmacological inhibition of poly(ADP-ribosyl)ation or PARP1 knockdown via RNA interference leads to a rapid decrease in telomere length and stabilization at a lower level. Importantly, neither the length of the single-stranded telomeric overhang nor telomerase activity was affected by PARP1 inhibition. Interestingly, release from PARP inhibition led to a fast regain in telomere length in telomerase-positive cells indicating that PARP1 activity is an important determinant in telomere length regulation [112]. On a molecular level, the function of PARP1 in telomere length regulation presumably depends on its interaction with the telomeric repeat binding factor 2 (TRF2). TRF2 is a key component of the shelterin complex and is responsible for telomeric stability, length regulation, and suppression of unscheduled activity of the double-strand break repair machinery by maintaining the t-loop [113]. PARP1 interacts with and modifies TRF2, and the poly(ADPribosyl)ation of TRF2 affects its binding to telomeric DNA $[111,114]$. 


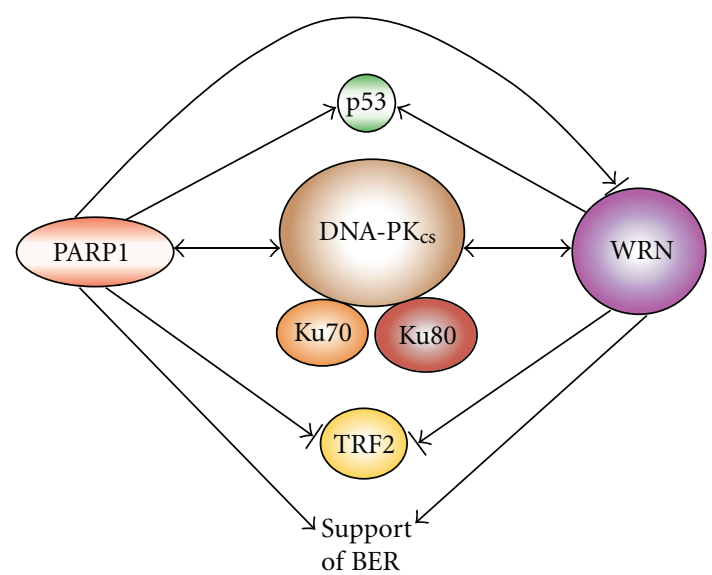

FIgURe 3: Interaction map between PARP1 and Werner syndrome protein (WRN). The two proteins share many overlapping interaction pathways. There is a reciprocal interaction with DNA-PK (double-headed arrow) and p53, stimulation of base excision repair (BER, one-headed arrow), and inhibition of TRF2-DNA binding (blocked arrow). PARP1 also inhibits WRN functions if in an unmodified state (reproduced from [113]).

Another PARP1 interaction partner that is involved in telomere regulation is the RecQ helicase WRN [115]. Patients with the rare autosomal recessive disorder Werner syndrome, in which the WRN gene is mutated, display genomic instability and telomere shortening on the cellular and premature aging on the organismic level with symptoms resembling normal human aging in many aspects including cataracts, graying of hair and alopecia, atherosclerosis, osteoporosis, and higher cancer incidence. The premature aging phenotype of these patients appears to be at least partially dependent on telomere length, since human symptoms were only recapitulated in mice with short telomeres, that is, WRN/telomerase double-knockout mice $[115,116]$. (N.B. Mice usually exhibit considerably longer telomeres $(\sim 40 \mathrm{~kb})$ than humans $(5-15 \mathrm{~kb}))$. On a cellular level, fibroblasts derived from WS patients display genomic instability and a reduced replicative lifespan. This phenotype is in accordance with experimental data demonstrating that WRN is involved in multiple aspects of DNA metabolism, such as DNA replication, genomic maintenance, and telomere regulation [115]. WRN functions as a $3^{\prime}-5^{\prime}$ helicase and additionally as a $3^{\prime}-5^{\prime}$ exonuclease. Proper enzymatic activity of WRN seems to be crucial for maintaining genomic integrity, since pharmacological inhibition of WRN's helicase activity causes DSBs and apoptosis [117]. WRN and PARP1 directly interact with each other physically and PARP1 modulates WRN's exonuclease and helicase activities [118, 119]. Upon automodification of PARP1, the inhibition of WRN's exonuclease and helicase activities is released suggesting that PARP1 regulates the timing of WRN activity towards its substrates [113]. The regulation of PARP1 and WRN appears to be reciprocal, because poly(ADP-ribosyl)ation is impaired in WRN deficient cells indicating that WRN is required to regulate PARP1-dependent poly(ADP-ribosyl)ation [120]. Moreover, other factors than PARP1 and WRN are involved in these mechanisms, because WRN and PARP1 share many interaction partners, including DNA-PK, P53, and TRF2 (Figure 3). For example, PARP1, WRN, and DNA-PK (including $\mathrm{Ku} 70 / 80$ and $\mathrm{DNA}-\mathrm{PK}_{\mathrm{cs}}$ ) can form a complex, in which PAR-modified Ku70/80 inhibits WRN [121]. Furthermore, both PARP1 and WRN have positive impact on telomere length, presumably by regulating the binding of TRF2 to the t-loop. Genetic cooperation between PARP1 and WRN was demonstrated in vivo, because mice with deficiencies in both proteins display higher rates of chromatid breaks, chromosomal rearrangements, and cancer than each of the single-mutant mice [122]. Moreover, double mutants appear to have reduced median and maximum lifespan, despite the fact that these mice were on a telomerase-positive genetic background and telomere lengths of single-mutant MEFs did not differ significantly from the double-mutant MEFs. This finding suggests that telomere-independent functions of WRN and PARP1 exist in the mouse to maintain organismic longevity. (N.B. In contrast, wild-type MEFs showed 30$40 \%$ longer telomeres). In conclusion, since PARP1 and WRN share many interaction partners and both proteins participate in other DNA repair pathways such as BER and NHEJ, they probably synergistically collaborate to maintain overall genomic stability and ensure longevity.

\subsection{PARP1 during DNA Replication, Mitosis, and Cell Cycle} Control. The WRN helicase also participates in the response to replicative stress, a cellular stressor that was linked to mammalian aging due to its ability to drive cells, including stem cells, into senescence and apoptosis [123, 124]. Replication forks contain several proteins such as helicases and polymerases, forming the so-called replisome. Usually, progression of the replication fork continues until it encounters a replication fork barrier such as DNA-protein complexes or SSBs. In this case, the replicative helicase progresses much more slowly, so that the fork is "stalled." If this goes along with the disassembly of the replisome the fork "collapses" and a DSBs is formed [125]. WRN and PARP1 are involved in the reactivation of stalled replication forks. Specifically, PARP1 binds to and is activated at stalled replication forks and mediates the recruitment of Mre11, a key component of the MRN complex. Mre11 may collaborate with WRN helicase to resect DNA ends for RAD51 loading and subsequent $\mathrm{HR}$ repair to promote replication fork restart after release from replication blocks $[44,107,125,126]$. In accordance with these data, a recent study demonstrated that PARP activity is required for effective replication fork restart upon treatment of cells with sublethal dosis of the replication stress-inducing topoisomerase 1 inhibitor camptothecin [127].

After DNA replication is completed, proper mitotic regulation is crucial to ensure genomic integrity [128]. During mitosis, the spindle pole formation requires the centrosome, whereas the centromere is the chromosomal region that organizes the kinetochore, thus enabling the attachment of the mitotic spindle microtubules. First, evidence for a role of poly(ADP-ribosyl)ation in spindle regulation was obtained from a study with Xenopus laevis egg extracts showing that $\mathrm{PAR}$ is a component of the mitotic spindle and is required for 
its assembly and function, although this was attributed to the enzymatic activity of another PARP family member, that is, tankyrase-1 $[129,130]$. With regards to PARP1, it was shown that haploinsufficiency for PARP1 is related to centrosome duplication and chromosomal instability [131]. Consistent with this, PARP1 localizes to the centrosome [132, 133]. Moreover, PARP1 and PARP2 are present at centromeres and interact with the constitutive centromere proteins Cenpa, Cenpb and the spindle check point protein Bub3 [134, 135]. The physical and functional relationship of PARP1 to the centrosome and the centromere links DNA damage surveillance to the mitotic spindle checkpoint. The notion that mitotic spindle checkpoint proteins play an important role to ensure mammalian longevity is supported by studies demonstrating that mice with low levels of the mitotic checkpoint protein BubR1 and mice haploinsufficient for Bub3 and Rae1-another mitotic checkpoint gene-age prematurely (N.B. A complete knockout of these genes results in embryonic lethality in the mouse) $[136,137]$.

Because severe DNA damage or mitotic misregulation can cause genomic instability leading to tumor formation, a complex cellular security network has evolved to counteract carcinogenesis. This signaling network can stop the cell cycle at different stages, thereby either inducing DNA repair, or eradicating or neutralizing heavily damaged cells by apoptosis or senescence, respectively. To this end, apoptosis and senescence are powerful tumor-suppressive mechanisms, but on the other hand, both pathways can lead to depletion of the regenerative cell pool, thus promoting tissue degeneration and organ failure, which are hallmarks of aging [138]. One of the most important regulators of cell cycle progression and induction of senescence/apoptosis is the transcription factor P53. Consequently, mouse studies demonstrated that P53 deficiency leads to premature death due to tumor development, whereas constantly active P53 protects against cancer at the cost of a premature aging phenotype [138]. Consistent with the role of PARP1 and P53 as caretakers and guardians of the genome, respectively, PARP1 and P53 synergistically cooperate in vivo in telomere and chromosomal maintenance as well as in tumor suppression [139-143]. Many functional interactions between PARP1 and P53 during DNA damage response and apoptosis exist, such as delayed P53 transactivation potential in PARP1-deficient cells [144-147]. In addition to its function as a positive regulator of gene expression, P53 also acts as a gene-specific transcriptional transrepressor. Interestingly, P53-mediated transrepression of the MTA1 gene (MTA1, metastasis associated protein 1), a component of a nucleosome remodeling complex which is associated with very aggressive tumor phenotypes, depends on functional poly(ADP-ribosyl)ation of P53 [148]. On the other hand, poly(ADP-ribosyl)ation of P53 is also able to inhibit its binding to its transcriptional consensus sequence, indicating that multifaceted regulatory mechanisms exist between PARP1 and P53 [149, 150]. Kanai et al. suggested a mechanism of PARP1-dependent regulation of P53 activity. According to this study, poly(ADP-ribosyl)ation induces structural changes in P53 that mask its nuclear export sequence, resulting in an accumulation of P53 in the nucleus, where it exerts its transactivational functions. Accordingly, a P53 mutant in which acceptor sites were mutated was localized to the cytoplasm to a greater extent than wildtype P53 [151].

In conclusion, there is ample evidence that PARP1 modulates P53 stability, intracellular localization, and transcriptional activity with likely implications in the induction of apoptosis and senescence on a cellular and therefore aging and longevity on an organismic level. However, studying the combined role of PARP1 and P53 in the aging process is complicated by the situation that mouse models with deficiencies in both tumor-suppressor genes show cancer-dependent premature death unrelated to other signs of premature aging. The development of sophisticated conditional mouse models with spatiotemporal-controlled expression of PARP1 and P53 may represent an approach to overcome these hurdles.

3.5. PARP1 as a Longevity Assurance Factor. As discussed in the preceding sections, PARP1 acts as a general caretaker of genomic stability and is associated with various factors, whose involvement in mechanisms of aging and longevity are well established. This indicates a potential role of PARP1 as a longevity assurance factor which is supported by in vivo studies as briefly discussed in the following.

There is a large body of evidence showing a positive correlation of poly(ADP-ribosyl)ation capacity and mammalian longevity. Previously, we demonstrated that poly(ADPribosyl)ation capacity in peripheral blood mononuclear cells (PBMCs) of 13 mammalian species strongly correlates with their maximum lifespan, for example, maximum poly(ADPribosyl)ation levels were five times higher in humans than in rodents [152]. Interestingly, these differences in poly(ADPribosyl)ation are not associated with different enzyme levels, but are rather influenced by an higher poly(ADPribosyl)ation capacity of the human PARP1 enzyme in comparison to its mouse ortholgue [153]. Moreover, poly(ADPribosyl)ation capacity in PBMCs declines with age in humans and rodents [152, 154]. Interestingly, humans exhibiting an exceptional long lifespan, that is, centenarians, display a significantly higher poly(ADP-ribosyl)ation capacity than the average population [155], which is comparable to those of young subjects [156].

Apart from these correlative studies, studies with Parp $1^{-/-}$mice indicate a role of PARP1 as a longevity assurance factor. Thus, Parp $1^{-/-}$mice and cells derived thereof are hypersensitive to DNA-damaging agents and $\mathrm{Parp1}^{-/-}$ cells display increased spontaneous genomic instability as measured by the frequency of sister chromatid exchanges, chromosome aberrations, and micronuclei formation, which confirmed that PARP1 functions as a general caretaker of the genome [157]. In support of the view that PARP1 counteracts the aging process is the finding that Parp1 ${ }^{-/-}$ mice age is moderately faster compared to wild-type control animals [158]. Moreover, this and various other studies supported the notion that PARP1 acts as a tumor-suppressor gene, since PARP1 deficiency enhances carcinogenesis during aging and upon induction by DNA damaging agents [143, 158-161]. Consistently, data from human studies showed that a hypomorphic PARP1 polymorphism (V762A) serves 
as a risk factor in the development of some types of human cancers [162-166].

In conclusion, PARP1 participates in various genome maintenance mechanisms, such as chromatin remodeling, DNA repair, reactivation of stalled replication forks, telomere maintenance, and cell cycle control. Consistent with its role as a general caretaker of the genome, there is strong evidence from in vivo studies indicating that PARP1 indeed functions as a longevity assurance factor. On the other hand, the interaction of PARP1 with key regulators of immune function, such as NF- $\kappa \mathrm{B}$, and its potential to induce cell death may contribute to aging-promoting mechanisms as discussed in the following sections.

\section{PARP1 in Inflammation and Cell Death}

First, evidence that PARP1 contributes to inflammation and the development of related pathologies was revealed by genetic studies in $\operatorname{Parp}^{-/-}$mice, because these animals are protected from several inflammation and cell deathassociated pathologies such as ischemic infarction, collageninduced arthritis, and LPS-induced septic shock [157, 167]. Moreover, Parp $1^{-/}$animals are resistant to MPTP-induced Parkinson's disease and streptozotocin-induced diabetes mellitus [168-171]. The molecular and cellular mechanisms underlying these phenotypic results and their possible implications in mechanisms of aging and longevity are discussed below.

4.1. PARP1, NF- $\kappa B$, and Inflammation. Various studies demonstrated that PARP1 participates in the regulation of transcriptional processes, either via general chromatin remodeling or through specific interaction and regulation of a wide range of transcription factors [171, 172].

Maybe the best studied interaction is that of PARP1 with NF- $\kappa$ B. The transcription factor NF- $\kappa \mathrm{B}$ is considered a master regulator in controlling gene expression upon proinflammatory stimuli. NF- $\kappa \mathrm{B}$ is composed of dimeric combinations of Rel family members with the major subunits p65 and p50. In nonstimulated cells, NF- $\kappa \mathrm{B}$ is located in the cytoplasm via the binding to the inhibitory $\mathrm{I} \kappa \mathrm{B}$ proteins. Upon proinflammatory stimuli, I $\kappa \mathrm{B}$ proteins are phosphorylated by I $\kappa$ B kinases (IKKs), which cause their degradation by the ubiquitin/proteasome system. Subsequently, NF- $\kappa \mathrm{B}$ is translocated to the nucleus, where it can activate the transcription of a number of genes, especially inflammatory genes [173]. Apart from the regulation of NF$\kappa \mathrm{B}$ by its subcellular localization, its action is tightly regulated within the nucleus by posttranslational modifications and interaction with transcriptional cofactors. Importantly, NF$\kappa \mathrm{B}$-dependent gene expression is associated with aging in the mouse as well as in humans [174]. Recently, it was shown that hyperactive NF- $\kappa \mathrm{B}$ signaling contributes to premature aging in the mouse [175], and blocking of NF- $\kappa \mathrm{B}$ in aged mice was sufficient to reverse some features of skin aging $[174,176]$. In accordance with these studies, pharmacological inhibition of NF- $\kappa \mathrm{B}$ prolongs lifespan of Drosophila melanogaster by $\sim 15 \%$ [177]. Cellular studies showed that NF- $\kappa$ B-dependent

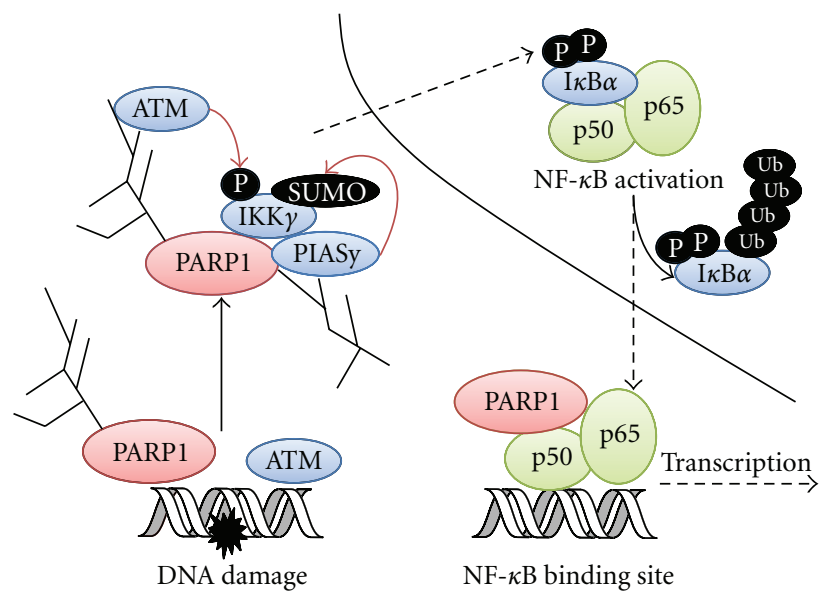

Figure 4: Simplified model of PARP1-dependent mechanisms of NF- $\kappa$ B activation. For details see text. Scheme based on $[167,185]$.

gene transcription can be induced by genotoxic stress and gene transcription studies in conditionally immortalized human fibroblast suggested that NF- $\kappa \mathrm{B}$ signaling plays a causal role in the development of senescence [178]. In addition, NF- $\kappa \mathrm{B}$ signaling was implicated in maintaining cellular senescence, because NF- $\kappa \mathrm{B}$-deficient fibroblasts escape senescence earlier and immortalize at a faster rate [179]. On the other hand, NF- $\kappa$ B-dependent gene transcription can be induced by genotoxic stress and is required for the transcription of many SASP factors [5]. In summary, there is substantial evidence that NF- $\kappa$ B plays a crucial role in aging and age-related diseases [180].

The expression and activation patterns of PARP1 and $\mathrm{NF}-\kappa \mathrm{B}$ are remarkably similar in various tissues. A direct role of PARP1 in NF- $\kappa$ B-mediated transcription was emphasized by the finding that expression of NF- $\kappa \mathrm{B}$-dependent proinflammatory mediators, such as TNF $\alpha$, IL6, or iNOS, is impaired in Parp $1^{-/-}$mice $[167,181]$. PARP1 physically interacts with both major subunits of NF- $\kappa \mathrm{B}$, that is, p65 and $\mathrm{p} 50$, and is required for NF- $\kappa \mathrm{B}$-dependent gene transcription (Figure 4) [182]. Moreover, PARP1 is acetylated by the histone acetylase p300/CBP upon inflammatory stimuli, leading to a stronger association with NF- $\kappa \mathrm{B}$ [39]. Subsequent expression of proinflammatory mediators such as iNOS leads to the production of highly reactive chemical species that, in turn, cause extensive DNA damage in the target cell, potentially supporting a positive feedback mechanism. Importantly, in this study neither the DNA binding nor the enzymatic activity of PARP1 was necessary for direct transcriptional activation of NF- $\kappa \mathrm{B}$ [183]. On the other hand, inhibition of PARP's enzymatic activity is sufficient to decrease the expression of iNOS, IL6, and TNF $\alpha$ in cultured cells and to reduce the expression of inflammatory mediators in mice [184]. This is consistent with a recent study demonstrating that the PARP1-dependent activation of NF- $\kappa \mathrm{B}$ occurs at two levels (Figure 4). Thus, in addition to the nuclear coactivator function of PARP1 on NF- $\kappa \mathrm{B}$ activity, this study identified PARP1 as a trigger for the translocation of NF- $\kappa B$ from the cytoplasm into the nucleus upon genotoxic stress (Figure 4) [185]. According to this 
model, PARP1 is recruited to DNA strand breaks and is automodified with PAR. Upon dissociation into the nucleoplasm, PARP1 then rapidly forms a signalosome composed of the SUMO1 ligase PIASy, IKK $\gamma$ (NEMO), and ATM. The signalosome is stabilized by a network of direct proteinprotein interactions as well as by PAR binding of PIASy and ATM through PAR binding motifs. PAR degradation by PARG causes subsequent destabilization of the signalosome, resulting in IKK $\gamma$ SUMOylation, translocation to the cytoplasm, phosphorylation of $\mathrm{I} \kappa \mathrm{B}$ proteins, and NF-kB activation. This mechanism directly links the DNA-damagesignaling functions of PARP1 to its role in inflammationrelated mechanisms. Interestingly, PARP1-NF- $\kappa \mathrm{B}$ signaling seems also to contribute to the activation and maintenance of the secretory phenotype of senescent cells [186]. In consequence, the associated secretion of proinflammatory factors possibly changes the tissue microenvironment and forms a site of low-level chronic inflammation with tumor and aging-promoting properties.

4.2. PARP1 and Its Role in Cell Death. Historically, two major mechanisms of mammalian cell death are distinguished, that is, apoptosis and necrosis. Apoptosis is considered as the default pathway, where cell death occurs in a controlled manner resulting in the elimination of cells by macrophages without secondary damage of the surrounding cells. In contrast, necrosis is considered an uncontrolled process which leads to disruption of cells promoting tissue inflammation [187]. Several transition states between the two pathways exist such as apoptosis inducing factor-(AIF-) dependent cell death [188]. Cell death is an important factor contributing to organismic aging, because apoptosis can lead to depletion of the regenerative cell pool and necrosis can cause chronic inflammatory conditions. PARP1 is involved in necrosis as well as in apoptosis, depending on the cell type and the intensity of DNA damage. Excessive DNA damage, as it can be triggered by pathophysiological stimuli and during NF$\kappa \mathrm{B}$-dependent inflammatory responses, leads to an overactivation of PARP1, which induces the depletion of cellular $\mathrm{NAD}^{+}$pools and subsequently of ATP pools [189]. This could affect energy-dependent cellular functions resulting in necrosis, which in turn reinforce tissue inflammation leading to a vicious cycle of PARP1 activation, necrosis, and inflammation. The role of PARP1 in apoptosis is manifold depending on the cell cycle state. Two major types of apoptosis exist: caspase-dependent and caspase-independent apoptosis. On the one hand, in proliferating cells, PARP1 contributes to classical caspase-dependent apoptosis through its regulatory activity on P53. Here, after an initial synthesis of PAR, PARP1 is cleaved by caspases 3 and 7 in a $24 \mathrm{kD}$ and an $89 \mathrm{kD}$ fragment [190]. This occurs potentially to inactivate PARP1 and to preserve cellular ATP pools for the apoptosis program [191-193]. On the other hand, it was shown that PARP1 contributes to caspase-independent apoptosis by releasing AIF from the mitochondria [194, 195]. PAR itself acts as a signaling molecule between nucleus and mitochondria, where it binds to AIF in a non-covalent manner and then triggers its release. AIF then translocates to the nucleus, where it causes chromatin condensation, largescale DNA fragmentation, and finally cell death [196-198].

In conclusion, three interconnected cellular mechanisms have been proposed to be responsible for the involvement of PARP1 in cell death and inflammation-related, agerelated pathologies. First, PARP1 overactivation by severe DNA damage upon an initial pathological insult can lead to $\mathrm{NAD}^{+}$and subsequent ATP depletion causing necrotic cell death due to energy depletion [189]. Second, such an initial pathological insult or secondary necrotic disruption of cells can trigger an inflammatory response leading to further damage of the surrounding tissue. This process can be stimulated by the action of PARP1 as an essential transcriptional coactivator of the proinflammatory transcription factor NF$\kappa \mathrm{B}$. Products of NF- $\kappa \mathrm{B}$ regulated genes, for example, iNOS, participate in the production of ROS and RNS, which could support the aforementioned vicious cycle of DNA damage, subsequent PARP1 activation, and cell death potentiating inflammation and tissue damage. Third, the PAR-dependent release of apoptosis-inducing factor (AIF) from the mitochondria resulting in caspase-independent apoptosis may contribute to some extent to PARP1-dependent pathologies in particular neurodegenerative disorders [194, 197, 198]. Over time, these mechanisms can contribute to aging and the development of age-related pathological conditions.

4.3. PARP1 as an Aging-Promoting Factor. Evidence supporting a role of PARP1 as a driving force of inflammation on an organismic level is given by the fact that $P a r p 1^{-/-}$ mice are protected from several inflammation- and celldeath-associated diseases and that $\mathrm{Parp1}^{-1-}$ mice and cells display lower expression levels of a whole spectrum of proinflammatory cytokines, adhesion molecules, and enzymes [167]. Consequently, given the role of inflammation during mammalian aging, PARP1 was postulated to act as an agingpromoting factor [199]. In line with this concept, PARP inhibition or ablation of gene transcription has beneficial effects on several age-related diseases, including agingassociated cardiac and vascular dysfunctions [184, 200, 201]. Apart from its functions as a regulator of NF- $\kappa \mathrm{B}$-dependent gene transcription, PARP1 competes with the family of type III histone deacetylases of sirtuins (i.e., in humans and mice SIRT1-7) for the same substrate, that is, $\mathrm{NAD}^{+}$. In addition, PARP1 and SIRT1 interact physically and show an antagonistic interplay on a functional level [71, 202]. Sirtuins regulate the energy homeostasis by controlling the acetylation status and activity of various enzymes and transcriptional regulators and have been identified to act as longevity factors in various species [203]. Moreover, consumption of $\mathrm{NAD}^{+}$links PARP1 and sirtuins to energy metabolism, which plays a fundamental role in aging mechanisms. In vivo studies showed that SIRT1-overexpressing mice are leaner, metabolically more active, show improved glucose tolerance, exhibit less inflammation, and are resistant to intestinal cancer development [204-208]. Parp $1^{-/-}$mice exhibit increased $\mathrm{NAD}^{+}$content and enhanced SIRT1 activity in brown adipose and muscle tissue. Consequently, Parp1 ${ }^{-/-}$ mice phenocopy many aspects of SIRT1 activation, such as a 


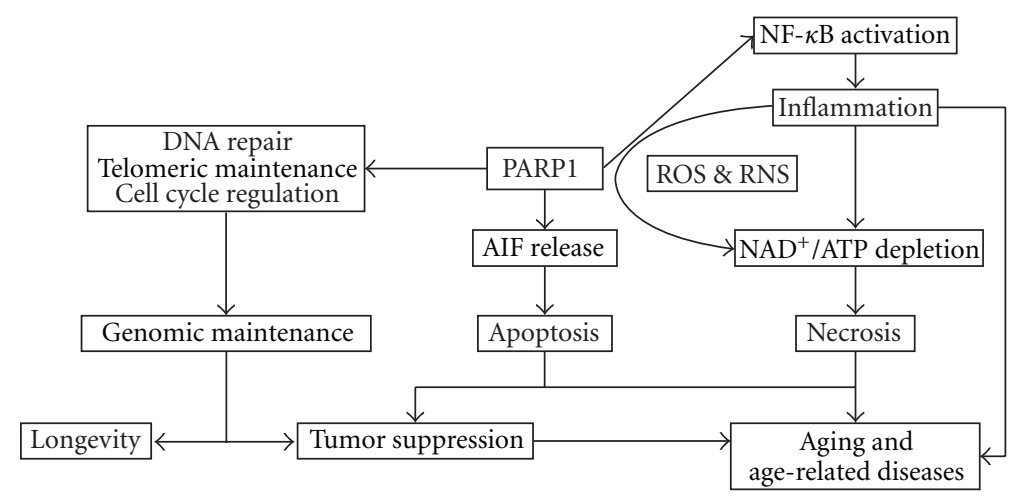

FIGURE 5: PARP1-related mechanisms in longevity and aging. For details see text.

higher mitochondrial content, increased energy expenditure, reduced body weight, and protection against metabolic disease [209].

Conversely, this phenotype is mirrored by the phenotype of mice with ectopic expression of hPARP1 [210]. These mice develop sporadic obesity and show impaired glucose tolerance. Furthermore, hPARP1-expressing mice exhibit impaired survival rates, which are accompanied by premature development of several inflammation and ageassociated pathologies, such as nephropathy, dermatitis, pneumonitis, myocardiopathy, and hepatitis. In support of this hypothesis, hPARP1 mice develop normocytic, normochromic anemia and show an increase in the fraction of circulating monocytes, which is suggestive of anemia of chronic inflammatory disease $[211,212]$. Moreover, $h P A R P 1$ mice show typical signs of premature aging, such as early development of kyphosis and impaired hair regrowth. In addition to a potentially altered interplay between PARP1 and sirtuins in these mice, the pathological phenotype of hPARP1 mice might be related to an altered PARP1-NF$\kappa \mathrm{B}$ interaction leading to a continuous low-level increase in pro-inflammatory stimuli. Consistently, expression of NF$\kappa \mathrm{B}$-dependent target genes, such as TNF $\alpha$, IL1, and IL6, is dysregulated in hPARP1 animals. This may contribute to the premature development of typical age-related chronic diseases in these mice [210].

\section{Summary}

Aging is a complex process which cannot be explained by a single pathway or even a set of closely related pathways. More likely, many diverse cellular functions will contribute to aging and they will do so in a highly interdependent manner [53]. As summarized here, this complexity is already represented at the level a single enzyme, that is, PARP1. PARP1 is a factor that connects DNA damage response and inflammatory mechanisms, both of which are closely associated with mammalian aging. Thus, under physiological conditions and mild genotoxic stress, PARP1 is thought to play an important role in genomic maintenance (Figure 5). On the other hand, under pathophysiological conditions, reactive chemical species are generated by activated immune cells potentially inducing DNA damage in an autocrine and paracrine fashion. If exceeding a threshold, DNA damage and the subsequent signaling can force cells into senescence. Senescent cells, in turn, possess the potential to secrete proinflammatory cytokines thereby reinforcing tissue inflammation. PARP1 is involved in these processes due to its close interplay with NF- $\kappa \mathrm{B}$ at different stages during NF$\kappa \mathrm{B}$ activation. In addition, severe DNA damage can trigger overactivation of PARP1 resulting in cell death by apoptosis or necrosis (Figure 5). Debris of necrotic cells is phagocytosed by macrophages, thereby triggering a proinflammatory response, again inducing the generation of reactive chemical species. Interestingly, there is some evidence that chronic intestinal inflammation can induce systemic genotoxicity, for example, in leukocytes and hepatocytes, suggesting that local sites of inflammation can affect genomic stability and homeostasis even at an organismic level [213]. Over time, inflammation, senescence, and cell death contribute to the depletion of the regenerative cell pool and tissue dysfunction accumulating in the aging process.

There is ample evidence supporting a role of PARP1 as a longevity assurance factor on the one hand, but also as an aging-promoting factor on the other hand.The dual role of PARP1 in longevity and aging might be reflected in the moderate premature aging phenotype observed in cohorts of $\mathrm{Parp1}^{-/-}$mice [158]. Thus, it is reasonable to assume that overall aging in these mice is kept nearly in balance, due to comprised genomic integrity on the one hand, but reduced inflammatory status on the other hand. The generation of Parp $^{-/-}$mice with tissue specific reconstitution of PARP1 expression may be a suitable model to test such a hypothesis. Tissue-specific reexpression of PARP1 in cells of the innate immune system on an otherwise Parp1 $1^{-/}$background may lead to a more drastic accelerated aging phenotype, since PARP1-overexpressing cells of the innate immune system are expected to exhibit an enhanced inflammatory status, while cells of the remaining Parp1 ${ }^{-/-}$tissues are genomically unstable. Another possibility explaining the moderate premature aging phenotype of $\operatorname{Parp}^{-/-}$mice may be that alternative mechanisms are able to compensate for the PARP1 deficiency. Such potential backup mechanisms rely most likely on PARP2 which shares some redundancy to PARP1, as it is evident by the finding that Parp1/Parp2 double-deficient mice are not viable. The generation of 
conditional and inducible double-knockout mice may help to test this hypothesis.

Many theories of aging exist. Most of these are not mutually exclusive and although none of these is probably able to explain all characteristics of human aging, in all probability there is some truth in many of them. The "antagonistic pleitropy" theory of aging postulates the existence of pleiotropic genes and mechanisms having opposite effects on fitness at different stages of age. Thus, a gene or mechanism may be beneficial for survival in early life, when natural selection is strong, but harmful at later ages, when selection is weak or absent [214]. Mechanisms of DNA damage response as well as inflammation may support such a theory. DNA damage response, with its final end points, DNA repair, senescence, and apoptosis, is clearly beneficial at young age, as these mechanisms prevent cancer development. However, at older age, this may become detrimental, as depletion of the regenerative cell pool by senescence or apoptosis may contribute to tissue degeneration and aging. The same holds true for inflammation. At young age, inflammatory responses most likely fulfill beneficial functions, for example, acting as a first line defense against infections. (N.B. This is supported by the finding that some mouse models with deficiencies in NF- $\kappa \mathrm{B}$ signaling are hypersensitive to infectious diseases [215]). However, at older age, continuous pressure on the immune system caused by repeated antigen stimulation leads to remodeling of the immune system with pro-inflammatory properties reinforcing the aging process and the development of age-related disease. Because PARP1 fulfills key roles in mechanisms of DNA damage response and inflammation, it is conceivable that functions of this gene act in some aspects in an antagonistic pleiotropic way, with beneficial functions in the youth and detrimental functions at old age.

In conclusion, PARP1 and the synthesis of poly(ADPribose) are emerging as central factors in general cellular stress response with functions in a plethora of molecular mechanisms, such as chromatin remodeling, transcription, DNA damage signaling, DNA repair, cell cycle regulation, cell death, and inflammation. As reviewed here, there is ample evidence that PARP1 fulfills numerous direct as well as indirect roles in mechanisms of aging and longevity which renders it an interesting factor to study in order to better define mechanisms of the aging process.

\section{Acknowledgements}

Our experimental work was supported by the DFG-funded Collaborative Research Center (CRC) 969, the Konstanz Research School Chemical Biology (KoRS-CB) and the International Research Training Group (IRTG) 1331. Funding for open access publishing was provided by University of Konstanz.

\section{References}

[1] B. R. Troen, "The biology of aging," Mount Sinai Journal of Medicine, vol. 70, no. 1, pp. 3-22, 2003.

[2] G. A. Garinis, G. T. J. van der Horst, J. Vijg, and J. H. J. Hoeijmakers, "DNA damage and ageing: new-age ideas for an age-old problem," Nature Cell Biology, vol. 10, no. 11, pp. 1241-1247, 2008.

[3] R. Medzhitov, "Inflammation 2010: new adventures of an old flame," Cell, vol. 140, no. 6, pp. 771-776, 2010.

[4] D. de Gonzalo-Calvo, K. Neitzert, M. Fernández et al., "Differential inflammatory responses in aging and disease: TNF- $\alpha$ and IL- 6 as possible biomarkers," Free Radical Biology and Medicine, vol. 49, no. 5, pp. 733-737, 2010.

[5] A. Freund, A. V. Orjalo, P. Y. Desprez, and J. Campisi, "Inflammatory networks during cellular senescence: causes and consequences," Trends in Molecular Medicine, vol. 16, no. 5, pp. 238-246, 2010.

[6] M. De Martinis, C. Franceschi, D. Monti, and L. Ginaldi, "Inflamm-ageing and lifelong antigenic load as major determinants of ageing rate and longevity," FEBS Letters, vol. 579, no. 10, pp. 2035-2039, 2005.

[7] J. Wang, H. Geiger, and K. L. Rudolph, "Immunoaging induced by hematopoietic stem cell aging," Current Opinion in Immunology, vol. 23, no. 4, pp. 532-536, 2011.

[8] A. Salminen, J. Huuskonen, J. Ojala, A. Kauppinen, K. Kaarniranta, and T. Suuronen, "Activation of innate immunity system during aging: NF- $\kappa \mathrm{B}$ signaling is the molecular culprit of inflamm-aging," Ageing Research Reviews, vol. 7, no. 2, pp. 83-105, 2008.

[9] D. Sarkar and P. B. Fisher, "Molecular mechanisms of agingassociated inflammation," Cancer Letters, vol. 236, no. 1, pp. 13-23, 2006.

[10] D. Harman, "Free radical theory of aging: an update-increasing the functional life span," Annals of the New York Academy of Sciences, vol. 1067, no. 1, pp. 10-21, 2006.

[11] P. Lonkar and P. C. Dedon, "Reactive species and DNA damage in chronic inflammation: reconciling chemical mechanisms and biological fates," International Journal of Cancer, vol. 128, no. 9, pp. 1999-2009, 2011.

[12] A. Mangerich, C. G. Knuston, N. M. Parry et al., "Infectioninduced colitis in mice causes dynamic and tissue-specific changes in stress response and DNA damage leading to colon cancer," Proceedings of the National Academy of Sciences of the United States of America, vol. 109, no. 27, pp. E1820-E1829, 2012.

[13] F. Rodier, J. P. Coppé, C. K. Patil et al., "Persistent DNA damage signalling triggers senescence-associated inflammatory cytokine secretion," Nature Cell Biology, vol. 11, no. 8, pp. 973-979, 2009.

[14] S. M. Chambers, C. A. Shaw, C. Gatza, C. J. Fisk, L. A. Donehower, and M. A. Goodell, "Aging hematopoietic stem cells decline in function and exhibit epigenetic dysregulation.", PLoS biology, vol. 5, no. 8, p. e201, 2007.

[15] G. Lepperdinger, "Inflammation and mesenchymal stem cell aging," Current Opinion in Immunology, vol. 23, no. 4, pp. 518-524, 2011.

[16] M. O. Hottiger, P. O. Hassa, B. Lüscher, H. Schüler, and F. Koch-Nolte, "Toward a unified nomenclature for mammalian ADP-ribosyltransferases," Trends in Biochemical Sciences, vol. 35, no. 4, pp. 208-219, 2010.

[17] J. M. Pleschke, H. E. Kleczkowska, M. Strohm, and F. R. Althaus, "Poly(ADP-ribose) binds to specific domains in DNA damage checkpoint proteins," Journal of Biological Chemistry, vol. 275, no. 52, pp. 40974-40980, 2000.

[18] J. P. Gagné, M. Isabelle, K. S. Lo et al., "Proteome-wide identification of poly(ADP-ribose) binding proteins and poly(ADP-ribose)-associated protein complexes," Nucleic Acids Research, vol. 36, no. 22, pp. 6959-6976, 2008. 
[19] I. Ahel, D. Ahel, T. Matsusaka et al., "Poly(ADP-ribose)binding zinc finger motifs in DNA repair/checkpoint proteins," Nature, vol. 451, no. 7174, pp. 81-85, 2008.

[20] M. Altmeyer, S. Messner, P. O. Hassa, M. Fey, and M. O. Hottiger, "Molecular mechanism of poly(ADP-ribosyl)ation by PARP1 and identification of lysine residues as ADP-ribose acceptor sites," Nucleic Acids Research, vol. 37, no. 11, pp. 3723-3738, 2009.

[21] A. J. Gottschalk, G. Timinszky, S. E. Kong et al., "Poly(ADPribosyl)ation directs recruitment and activation of an ATPdependent chromatin remodeler," Proceedings of the National Academy of Sciences of the United States of America, vol. 106, no. 33, pp. 13770-13774, 2009.

[22] G. Timinszky, S. Till, P. O. Hassa et al., "A macrodomaincontaining histone rearranges chromatin upon sensing PARP1 activation," Nature Structural and Molecular Biology, vol. 16, no. 9, pp. 923-929, 2009.

[23] A. Hakmé, H. K. Wong, F. Dantzer, and V. Schreiber, "The expanding field of poly(ADP-ribosyl)ation reactions. 'Protein Modifications: beyond the Usual Suspects' Review Series," EMBO Reports, vol. 9, no. 11, pp. 1094-1100, 2008.

[24] M. L. Meyer-Ficca, R. G. Meyer, D. L. Coyle, E. L. Jacobson, and M. K. Jacobson, "Human poly(ADP-ribose) glycohydrolase is expressed in alternative splice variants yielding isoforms that localize to different cell compartments," Experimental Cell Research, vol. 297, no. 2, pp. 521-532, 2004.

[25] M. Niere, S. Kernstock, F. Koch-Nolte, and M. Ziegler, "Functional localization of two poly(ADP-ribose)-degrading enzymes to the mitochondrial matrix," Molecular and Cellular Biology, vol. 28, no. 2, pp. 814-824, 2008.

[26] W. K. Min, U. Cortes, Z. Herceg, W. M. Tong, and Z. Q. Wang, "Deletion of the nuclear isoform of poly(ADP-ribose) glycohydrolase (PARG) reveals its function in DNA repair, genomic stability and tumorigenesis," Carcinogenesis, vol. 31, no. 12, pp. 2058-2065, 2010.

[27] S. Oka, J. Kato, and J. Moss, "Identification and characterization of a mammalian 39-kDa poly(ADP-ribose) glycohydrolase," Journal of Biological Chemistry, vol. 281, no. 2, pp. 705-713, 2006.

[28] M. Niere, M. Mashimo, L. Agledal et al., "ADP-ribosylhydrolase 3 (ARH3), not poly-ADP-ribose glycohydrolase (PARG) isoforms, are responsible for degradation of mitochondrial matrix-associated poly-ADP-ribose," Journal of Biological Chemistry, vol. 287, no. 20, pp. 16088-16102, 2012.

[29] M. Rouleau, A. Patel, M. J. Hendzel, S. H. Kaufmann, and G. G. Poirier, "PARP inhibition: PARP1 and beyond," Nature Reviews Cancer, vol. 10, no. 4, pp. 293-301, 2010.

[30] E. Pion, G. M. Ullmann, J. C. Amé, D. Gérard, G. De Murcia, and E. Bombarda, "DNA-induced dimerization of poly(ADP-ribose) polymerase-1 triggers its activation," Biochemistry, vol. 44, no. 44, pp. 14670-14681, 2005.

[31] H. Mendoza-Alvarez and R. Alvarez-Gonzalez, "Poly(ADPribose) polymerase is a catalytic dimer and the automodification reaction is intermolecular," Journal of Biological Chemistry, vol. 268, no. 30, pp. 22575-22580, 1993.

[32] M. F. Langelier, J. L. Planck, S. Roy, and J. M. Pascal, "Structural basis for DNA damage-dependent poly(ADPribosyl)ation by human PARP-1," Science, vol. 336, no. 6082, pp. 728-732, 2012.

[33] A. A. Ali, R. Arribas-Bosacoma, M. Kozlowski et al., "The zinc-finger domains of PARP1 cooperate to recognize DNA strand breaks," Nature Structural \& Molecular Biology, vol. 19, no. 7, pp. 685-692, 2012.
[34] W. M. Shieh, J. C. Amé, M. V. Wilson et al., "Poly(ADPribose) polymerase null mouse cells synthesize ADP-ribose polymers," Journal of Biological Chemistry, vol. 273, no. 46, pp. 30069-30072, 1998.

[35] J. C. Amé, V. Rolli, V. Schreiber et al., "PARP-2, a novel mammalian DNA damage-dependent poly(ADP-ribose) polymerase," Journal of Biological Chemistry, vol. 274, no. 25, pp. 17860-17868, 1999.

[36] S. Messner, D. Schuermann, M. Altmeyer et al., "Sumoylation of poly(ADP-ribose) polymerase 1 inhibits its acetylation and restrains transcriptional coactivator function," FASEB Journal, vol. 23, no. 11, pp. 3978-3989, 2009.

[37] J. W. Walker, H. B. Jijon, and K. L. Madsen, "AMP-activated protein kinase is a positive regulator of poly(ADP-ribose) polymerase," Biochemical and Biophysical Research Communications, vol. 342, no. 1, pp. 336-341, 2006.

[38] T. M. Kauppinen, W. Y. Chan, S. W. Suh, A. K. Wiggins, E. J. Huang, and R. A. Swanson, "Direct phosphorylation and regulation of poly(ADP-ribose) polymerase-1 by extracellular signal-regulated 1/2," Proceedings of the National Academy of Sciences of the United States of America, vol. 103, no. 18, pp. 7136-7141, 2006.

[39] P. O. Hassa, S. S. Haenni, C. Buerki et al., "Acetylation of poly(ADP-ribose) polymerase-1 by p300/CREB-binding protein regulates coactivation of NF- $\kappa \mathrm{B}$-dependent transcription," Journal of Biological Chemistry, vol. 280, no. 49, pp. 40450-40464, 2005.

[40] M. Cohen-Armon, L. Visochek, D. Rozensal et al., "DNAindependent PARP-1 activation by phosphorylated ERK2 increases Elk1 activity: a link to histone acetylation," Molecular Cell, vol. 25, no. 2, pp. 297-308, 2007.

[41] R. Midorikawa, Y. Takei, and N. Hirokawa, "KIF4 motor regulates activity-dependent neuronal survival by suppressing PARP-1 enzymatic activity," Cell, vol. 125, no. 2, pp. 371-383, 2006.

[42] F. Berger, C. Lau, and M. Ziegler, "Regulation of poly(ADPribose) polymerase 1 activity by the phosphorylation state of the nuclear NAD biosynthetic enzyme NMN adenylyl transferase 1," Proceedings of the National Academy of Sciences of the United States of America, vol. 104, no. 10, pp. 37653770, 2007.

[43] T. Guastafierro, B. Cecchinelli, M. Zampieri et al., "CCCTCbinding factor activates PARP-1 affecting DNA methylation machinery," Journal of Biological Chemistry, vol. 283, no. 32, pp. 21873-21880, 2008.

[44] J. F. Haince, D. McDonald, A. Rodrigue et al., "PARP1dependent kinetics of recruitment of MRE11 and NBS1 proteins to multiple DNA damage sites," Journal of Biological Chemistry, vol. 283, no. 2, pp. 1197-1208, 2008.

[45] O. Mortusewicz, J. C. Amé, V. Schreiber, and H. Leonhardt, "Feedback-regulated poly(ADP-ribosyl)ation by PARP-1 is required for rapid response to DNA damage in living cells," Nucleic Acids Research, vol. 35, no. 22, pp. 7665-7675, 2007.

[46] J. H. Küpper, M. Muller, M. K. Jacobson et al., "transDominant inhibition of poly(ADP-ribosyl)ation sensitizes cells against $\gamma$-irradiation and $\mathrm{N}$-methyl-N'-nitro-Nnitrosoguanidine but does not limit DNA replication of a polyomavirus replicon," Molecular and Cellular Biology, vol. 15, no. 6, pp. 3154-3163, 1995.

[47] M. Masutani, T. Nozaki, E. Nishiyama et al., "Function of poly(ADP-ribose) polymerase in response to DNA damage: gene-disruption study in mice," Molecular and Cellular Biochemistry, vol. 193, no. 1-2, pp. 149-152, 1999. 
[48] C. Trucco, F. J. Oliver, G. De Murcia, and J. Ménissier-De Murcia, "DNA repair defect in poly(ADP-ribose) polymerase-deficient cell lines," Nucleic Acids Research, vol. 26, no. 11, pp. 2644-2649, 1998.

[49] J. M. De Murcia, C. Niedergang, C. Trucco et al., "Requirement of poly(ADP-ribose) polymerase in recovery from DNA damage in mice and in cells," Proceedings of the National Academy of Sciences of the United States of America, vol. 94, no. 14, pp. 7303-7307, 1997.

[50] Z. Q. Wang, L. Stingl, C. Morrison et al., "PARP is important for genomic stability but dispensable in apoptosis," Genes and Development, vol. 11, no. 18, pp. 2347-2358, 1997.

[51] R. Meyer, M. Muller, S. Beneke, J.-H. Küpper, and A. Bürkle, "Negative regulation of alkylation-induced sister-chromatid exchange by poly(ADP-ribose) polymerase-1 activity," International Journal of Cancer, vol. 88, no. 3, pp. 351-355, 2000.

[52] K. Weidele, A. Kunzmann, M. Schmitz, S. Beneke, and A. Bürkle, "Ex vivo supplementation with nicotinic acid enhances cellular poly(ADP-ribosyl)ation and improves cell viability in human peripheral blood mononuclear cells," Biochemical Pharmacology, vol. 80, no. 7, pp. 1103-1112, 2010.

[53] G. Pegoraro and T. Misteli, "The central role of chromatin maintenance in aging," Aging, vol. 1, no. 12, pp. 1017-1022, 2009.

[54] M. Rouleau, R. A. Aubin, and G. G. Poirier, "Pol (ADPribosyl)ated chromatin domains: access granted," Journal of Cell Science, vol. 117, no. 6, pp. 815-825, 2004.

[55] D. Quénet, V. Gasser, L. Fouillen et al., "The histone subcode: poly(ADP-ribose) polymerase-1 (Parp-1) and Parp-2 control cell differentiation by regulating the transcriptional intermediary factor TIF1 $\beta$ and the heterochromatin protein HP $1 \alpha$," FASEB Journal, vol. 22, no. 11, pp. 3853-3865, 2008.

[56] M. J. Gamble and R. P. Fisher, "SET and PARP1 remove DEK from chromatin to permit access by the transcription machinery," Nature Structural and Molecular Biology, vol. 14, no. 6, pp. 548-555, 2007.

[57] D. Ditsworth, W. X. Zong, and C. B. Thompson, "Activation of poly(ADP)-ribose polymerase (PARP-1) induces release of the pro-inflammatory mediator HMGB1 from the nucleus," Journal of Biological Chemistry, vol. 282, no. 24, pp. 1784517854, 2007.

[58] S. Messner, M. Altmeyer, H. Zhao et al., "PARP1 ADP-ribosylates lysine residues of the core histone tails," Nucleic Acids Research, vol. 38, no. 19, Article ID gkq463, pp. 6350-6362, 2010.

[59] F. Kappes, J. Fahrer, M. S. Khodadoust et al., "DEK is a poly(ADP-ribose) acceptor in apoptosis and mediates resistance to genotoxic stress," Molecular and Cellular Biology, vol. 28, no. 10, pp. 3245-3257, 2008.

[60] G. G. Poirier, G. De Murcia, and J. Jongstra-Bilen, "Poly (ADP-ribosyl)ation of polynucleosomes causes relaxation of chromatin structure," Proceedings of the National Academy of Sciences of the United States of America, vol. 79, no. 11, pp. 3423-3427, 1982.

[61] G. de Murcia, A. Huletsky, and D. Lamarres, "Modulation of chromatin superstructure induced by poly(ADP-ribose) synthesis and degradation," Journal of Biological Chemistry, vol. 261, no. 15, pp. 7011-7017, 1986.

[62] F. R. Althaus, "Poly ADP-ribosylation: a histone shuttle mechanism in DNA excision repair," Journal of Cell Science, vol. 102, no. 4, pp. 663-670, 1992.

[63] C. A. Realini and F. R. Althaus, "Histone shuttling by poly(ADP-ribosylation)," Journal of Biological Chemistry, vol. 267, no. 26, pp. 18858-18865, 1992.
[64] M. Y. Kim, S. Mauro, N. Gévry, J. T. Lis, and W. L. Kraus, "NAD+-dependent modulation of chromatin structure and transcription by nucleosome binding properties of PARP-1," Cell, vol. 119, no. 6, pp. 803-814, 2004.

[65] R. Krishnakumar, M. J. Gamble, K. M. Frizzell, J. G. Berrocal, M. Kininis, and W. L. Kraus, "Reciprocal binding of PARP1 and histone $\mathrm{H} 1$ at promoters specifies transcriptional outcomes," Science, vol. 319, no. 5864, pp. 819-821, 2008.

[66] G. M. Kavanaugh, T. M. Wise-Draper, R. J. Morreale et al., "The human DEK oncogene regulates DNA damage response signaling and repair," Nucleic Acids Research, vol. 39, no. 17, pp. 7465-7476, 2011.

[67] J. Fahrer, O. Popp, M. Malanga et al., "High-affinity interaction of poly(ADP-ribose) and the human DEK oncoprotein depends upon chain length," Biochemistry, vol. 49, no. 33, pp. 7119-7130, 2010.

[68] B. G. Ju, V. V. Lunyak, V. Perissi et al., "A topoisomerase II $\beta$ mediated dsDNA break required for regulated transcription," Science, vol. 312, no. 5781, pp. 1798-1802, 2006.

[69] M. Zerfaoui, K. Davis, S. Banerjee, A. Friggeri, C. Bell, and E. Abraham, "Poly(ADP-ribosyl)ation of high mobility group box 1 (HMGB1) protein enhances inhibition of efferocytosis," Molecular Medicine, vol. 18, no. 1, pp. 359-369, 2012.

[70] D. Ahel, Z. Hořejší, N. Wiechens et al., "Poly(ADP-ribose)dependent regulation of DNA repair by the chromatin remodeling enzyme ALC1," Science, vol. 325, no. 5945, pp. 1240-1243, 2009.

[71] S. B. Rajamohan, V. B. Pillai, M. Gupta et al., "SIRT1 promotes cell survival under stress by deacetylation-dependent deactivation of poly(ADP-ribose) polymerase 1," Molecular and Cellular Biology, vol. 29, no. 15, pp. 4116-4129, 2009.

[72] D. M. Chou, B. Adamson, N. E. Dephoure et al., "A chromatin localization screen reveals poly (ADP ribose)-regulated recruitment of the repressive polycomb and NuRD complexes to sites of DNA damage," Proceedings of the National Academy of Sciences of the United States of America, vol. 107, no. 43, pp. 18475-18480, 2010.

[73] G. Pegoraro, N. Kubben, U. Wickert, H. Göhler, K. Hoffmann, and T. Misteli, "Ageing-related chromatin defects through loss of the NURD complex," Nature Cell Biology, vol. 11, no. 10, pp. 1261-1267, 2009.

[74] A. Tulin and A. Spradling, "Chromatin loosening by poly (ADP)-ribose polymerase (PARP) at Drosophila puff loci," Science, vol. 299, no. 5606, pp. 560-562, 2003.

[75] C. M. Simbulan-Rosenthal, D. H. Ly, D. S. Rosentha et al., "Misregulation of gene expression in primary fibroblasts lacking poly(ADP-ribose)polymerase," Proceedings of the National Academy of Sciences of the United States of America, vol. 97, no. 21, pp. 11274-11279, 2000.

[76] F. Deschênes, C. Garand, and M. Lebel, "In vivo misregulation of genes involved in apoptosis, development and oxidative stress in mice lacking both functional Werner syndrome protein and poly(ADP-ribose) polymerase-1," Human Molecular Genetics, vol. 14, no. 21, pp. 3293-3308, 2005.

[77] G. Xu, M. Herzig, V. Rotrekl, and C. A. Walter, "Base excision repair, aging and health span," Mechanisms of Ageing and Development, vol. 129, no. 7-8, pp. 366-382, 2008.

[78] J. H. J. Hoeijmakers, "Genome maintenance mechanisms for preventing cancer," Nature, vol. 411, no. 6835, pp. 366-374, 2001.

[79] G. Gradwohl, J. Menissier De Murcia, M. Molinete et al., "The second zinc-finger domain of poly(ADP-ribose) polymerase determines specificity for single-stranded breaks in DNA," Proceedings of the National Academy of Sciences of 
the United States of America, vol. 87, no. 8, pp. 2990-2994, 1990.

[80] M. Molinete, W. Vermeulen, A. Bürkle et al., "Overproduction of the poly(ADP-ribose) polymerase DNA-binding domain blocks allkylation-induced DNA repair synthesis in mammalian cells," EMBO Journal, vol. 12, no. 5, pp. 21092117, 1993.

[81] H. N. Noren, K. Kompaniez, J. Barnes, A. Lohani, and M. K. Evans, "Poly(ADP-ribose) polymerase 1 (PARP-1) binds to 8oxoguanine-DNA glycosylase (OGG1)," Journal of Biological Chemistry, vol. 286, no. 52, pp. 44679-44690, 2011.

[82] M. Masson, C. Niedergang, V. Schreiber, S. Muller, J. Menissier-De Murcia, and G. De Murcia, "XRCC1 is specifically associated with poly(ADP-ribose) polymerase and negatively regulates its activity following DNA damage," Molecular and Cellular Biology, vol. 18, no. 6, pp. 3563-3571, 1998.

[83] S. F. El-Khamisy, M. Masutani, H. Suzuki, and K. W. Caldecott, "A requirement for PARP-1 for the assembly or stability of XRCC1 nuclear foci at sites of oxidative DNA damage," Nucleic Acids Research, vol. 31, no. 19, pp. 55265533, 2003.

[84] K. W. Caldecott, S. Aoufouchi, P. Johnson, and S. Shall, "XRCC1 polypeptide interacts with DNA polymerase $\beta$ and possibly poly (ADP-ribose) polymerase, and DNA ligase III is a novel molecular 'nick-sensor' in vitro," Nucleic Acids Research, vol. 24, no. 22, pp. 4387-4394, 1996.

[85] J. B. Leppard, Z. Dong, Z. B. Mackey, and A. E. Tomkinson, "Physical and functional interaction between DNA ligase III $\alpha$ and poly(ADP-ribose) polymerase 1 in DNA single-strand break repair," Molecular and Cellular Biology, vol. 23, no. 16, pp. 5919-5927, 2003.

[86] N. F. Confer, S. R. Kumari, and R. Alvarez-Gonzalez, "Biochemical association of poly(ADP-ribose) polymerase-1 and its apoptotic peptide fragments with DNA polymerase beta.," Chemistry \& Biodiversity, vol. 1, no. 10, pp. 1476-1486, 2004.

[87] V. Schreiber, J. C. Amé, P. Dollé et al., "Poly(ADP-ribose) polymerase-2 (PARP-2) is required for efficient base excision DNA repair in association with PARP-1 and XRCC1," Journal of Biological Chemistry, vol. 277, no. 25, pp. 23028-23036, 2002.

[88] J. Ménissier de Murcia, M. Ricoul, L. Tartier et al., "Functional interaction between PARP-1 and PARP-2 in chromosome stability and embryonic development in mouse," EMBO Journal, vol. 22, no. 9, pp. 2255-2263, 2003.

[89] O. Mortusewicz, J. C. Amé, V. Schreiber, and H. Leonhardt, "Feedback-regulated poly(ADP-ribosyl)ation by PARP-1 is required for rapid response to DNA damage in living cells," Nucleic Acids Research, vol. 35, no. 22, pp. 7665-7675, 2007.

[90] J. Fahrer, R. Kranaster, M. Altmeyer, A. Marx, and A. Bürkle, "Quantitative analysis of the binding affinity of poly(ADPribose) to specific binding proteins as a function of chain length,” Nucleic Acids Research, vol. 35, no. 21, p. e143, 2007.

[91] T. Thorslund, C. Von Kobbe, J. A. Harrigan et al., "Cooperation of the Cockayne syndrome group B protein and poly(ADP-ribose) polymerase 1 in the response to oxidative stress," Molecular and Cellular Biology, vol. 25, no. 17, pp. 7625-7636, 2005.

[92] C. Flohr, A. Bürke, J. P. Radicella, and B. Epe, "Poly(ADPribosyl)ation accelerates DNA repair in a pathway dependent on Cockayne syndrome B protein," Nucleic Acids Research, vol. 31, no. 18, pp. 5332-5337, 2003.

[93] M. M. Ghodgaonkar, N. Zacal, S. Kassam, A. J. Rainbow, and G. M. Shah, "Depletion of poly(ADP-ribose) polymerase-1 reduces host cell reactivation of a UV-damaged adenovirusencoded reporter gene in human dermal fibroblasts," DNA Repair, vol. 7, no. 4, pp. 617-632, 2008.

[94] M. Shrivastav, L. P. De Haro, and J. A. Nickoloff, "Regulation of DNA double-strand break repair pathway choice," Cell Research, vol. 18, no. 1, pp. 134-147, 2008.

[95] M. Wang, W. Wu, W. Wu et al., "PARP-1 and Ku compete for repair of DNA double strand breaks by distinct NHEJ pathways," Nucleic Acids Research, vol. 34, no. 21, pp. 61706182, 2006.

[96] R. Aguilar-Quesada, J. A. Muñoz-Gámez, D. Martín-Oliva et al., "Interaction between ATM and PARP-1 in response to DNA damage and sensitization of ATM deficient cells through PARP inhibition," BMC Molecular Biology, vol. 8, p. 29, 2007.

[97] J. F. Haince, S. Kozlov, V. L. Dawson et al., "Ataxia telangiectasia mutated (ATM) signaling network is modulated by a novel poly(ADP-ribose)-dependent pathway in the early response to DNA-damaging agents," Journal of Biological Chemistry, vol. 282, no. 22, pp. 16441-16453, 2007.

[98] T. Ruscetti, B. E. Lehnert, J. Halbrook et al., "Stimulation of the DNA-dependent protein kinase by poly(ADP-ribose) polymerase," Journal of Biological Chemistry, vol. 273, no. 23, pp. 14461-14467, 1998.

[99] L. Spagnolo, J. Barbeau, and N. J. Curtin, "Visualization of a DNA-PK/PARP1 complex," Nucleic Acids Research, vol. 40, no. 9, pp. 4168-4177, 2012.

[100] M. Audebert, B. Salles, and P. Calsou, "Involvement of poly (ADP-ribose) polymerase-1 and XRCC1/DNA ligase III in an alternative route for DNA double-strand breaks rejoining," Journal of Biological Chemistry, vol. 279, no. 53, pp. 5511755126, 2004.

[101] J. Domínguez-Bendala, M. Masutani, and J. McWhir, "Down-regulation of PARP-1, but not of Ku80 or DNAPKcs, results in higher gene targeting efficiency," Cell Biology International, vol. 30, no. 4, pp. 389-393, 2006.

[102] A. S. Waldman and B. C. Waldman, "Stimulation of intrachromosomal homologous recombination in mammalian cells by an inhibitor of poly(ADP-ribosylation)," Nucleic Acids Research, vol. 19, no. 21, pp. 5943-5947, 1991.

[103] A. Semionov, D. Cournoyer, and T. Y. K. Chow, "1,5Isoquinolinediol increases the frequency of gene targeting by homologous recombination in mouse fibroblasts," Biochemistry and Cell Biology, vol. 81, no. 1, pp. 17-24, 2003.

[104] H. E. Bryant, N. Schultz, H. D. Thomas et al., "Specific killing of BRCA2-deficient tumours with inhibitors of poly(ADPribose) polymerase," Nature, vol. 434, no. 7035, pp. 913-917, 2005.

[105] A. G. Patel, J. N. Sarkaria, and S. H. Kaufmann, "Nonhomologous end joining drives poly(ADP-ribose) polymerase (PARP) inhibitor lethality in homologous recombinationdeficient cells," Proceedings of the National Academy of Sciences of the United States of America, vol. 108, no. 8, pp. 34063411, 2011.

[106] D. C. Hegan, Y. Lu, G. C. Stacheleka, M. E. Crosbya, R. S. Bindraa, and P. M. Glazer, "Inhibition of poly(ADP-ribose) polymerase down-regulates BRCA1 and RAD51 in a pathway mediated by E2F4 and p130," Proceedings of the National Academy of Sciences of the United States of America, vol. 107, no. 5, pp. 2201-2206, 2010.

[107] H. E. Bryant, E. Petermann, N. Schultz et al., "PARP is activated at stalled forks to mediate Mre11-dependent replication restart and recombination," EMBO Journal, vol. 28, no. 17, pp. 2601-2615, 2009. 
[108] Z. Mao, C. Hine, X. Tian et al., "SIRT6 promotes DNA repair under stress by activating PARP1," Science, vol. 332, no. 6036, pp. 1443-1446, 2011.

[109] M. A. Blasco, "Telomeres and human disease: ageing, cancer and beyond," Nature Reviews Genetics, vol. 6, no. 8, pp. 611622, 2005.

[110] F. D. Di Fagagna, M. P. Hande, W. M. Tong, P. M. Lansdorp, Z. Q. Wang, and S. P. Jackson, "Functions of poly (ADP-ribose) polymerase in controlling telomere length and chromosomal stability," Nature Genetics, vol. 23, no. 1, pp. 76-80, 1999.

[111] M. Gomez, J. Wu, V. Schreiber et al., "PARP1 is a TRF2associated poly(ADP-ribose)polymerase and protects eroded telomeres," Molecular Biology of the Cell, vol. 17, no. 4, pp. 1686-1696, 2006.

[112] S. Beneke, O. Cohausz, M. Malanga, P. Boukamp, F. Althaus, and A. Bürkle, "Rapid regulation of telomere length is mediated by poly(ADP-ribose) polymerase-1," Nucleic Acids Research, vol. 36, no. 19, pp. 6309-6317, 2008.

[113] S. Beneke and A. Bürkle, "Survey and summary: poly(ADPribosyl)ation in mammalian ageing," Nucleic Acids Research, vol. 35, no. 22, pp. 7456-7465, 2007.

[114] M. S. O’Connor, A. Safari, D. Liu, J. Qin, and Z. Songyang, "The human Rap1 protein complex and modulation of telomere length," Journal of Biological Chemistry, vol. 279, no. 27, pp. 28585-28591, 2004.

[115] M. L. Rossi, A. K. Ghosh, and V. A. Bohr, "Roles of Werner syndrome protein in protection of genome integrity," DNA Repair, vol. 9, no. 3, pp. 331-344, 2010.

[116] S. Chang, A. S. Multani, N. G. Cabrera et al., "Essential role of limiting telomeres in the pathogenesis of Werner syndrome," Nature Genetics, vol. 36, no. 8, pp. 877-882, 2004.

[117] M. Aggarwal, J. A. Sommers, R. H. Shoemaker, and R. M. Brosh, "Inhibition of helicase activity by a small molecule impairs Werner syndrome helicase (WRN) function in the cellular response to DNA damage or replication stress," Proceedings of the National Academy of Sciences of the United States of America, vol. 108, no. 4, pp. 1525-1530, 2011.

[118] C. von Kobbe, J. A. Harrigan, V. Schreiber et al., "Poly(ADPribose) polymerase 1 regulates both the exonuclease and helicase activities of the Werner syndrome protein," Nucleic Acids Research, vol. 32, no. 13, pp. 4003-4014, 2004.

[119] C. Adelfalk, M. Kontou, M. Hirsch-Kauffmann, and M. Schweiger, "Physical and functional interaction of the Werner syndrome protein with poly-ADP ribosyl transferase," FEBS Letters, vol. 554, no. 1-2, pp. 55-58, 2003.

[120] C. Von Kobbe, J. A. Harrigan, A. May et al., "Central role for the Werner syndrome protein/poly(ADP-Ribose) polymerase 1 complex in the poly(ADP-Ribosyl)ation pathway after DNA damage," Molecular and Cellular Biology, vol. 23, no. 23, pp. 8601-8613, 2003.

[121] B. Li, S. Navarro, N. Kasahara, and L. Comai, "Identification and biochemical characterization of a Werner's syndrome protein complex with Ku70/80 and poly(ADP-ribose) polymerase-1," Journal of Biological Chemistry, vol. 279, no. 14, pp. 13659-13667, 2004.

[122] M. Lebel, J. Lavoie, I. Gaudreault, M. Bronsard, and R. Drouint, "Genetic cooperation between the Werner syndrome protein and poly(ADP-ribose) polymerase-1 in preventing chromatid breaks, complex chromosomal rearrangements, cancer in mice," American Journal of Pathology, vol. 162, no. 5, pp. 1559-1569, 2003.
[123] Y. Ruzankina, A. Asare, and E. J. Brown, "Replicative stress, stem cells and aging," Mechanisms of Ageing and Development, vol. 129, no. 7-8, pp. 460-466, 2008.

[124] W. C. Burhans and M. Weinberger, "DNA replication stress, genome instability and aging," Nucleic Acids Research, vol. 35, no. 22, pp. 7545-7556, 2007.

[125] R. M. Jones and E. Petermann, "Replication fork dynamics and the DNA damage response," Biochemical Journal, vol. 443, no. 1, pp. 13-26, 2012.

[126] Y. G. Yang, U. Cortes, S. Patnaik, M. Jasin, and Z. Q. Wang, "Ablation of PARP-1 does not interfere with the repair of DNA double-strand breaks, but compromises the reactivation of stalled replication forks," Oncogene, vol. 23, no. 21, pp. 3872-3882, 2004.

[127] A. Ray Chaudhuri, Y. Hashimoto, R. Herrador et al., "Topoisomerase i poisoning results in PARP-mediated replication fork reversal," Nature Structural and Molecular Biology, vol. 19, no. 4, pp. 417-423, 2012.

[128] J. M. Scholey, I. Brust-Mascher, and A. Mogilner, "Cell division,” Nature, vol. 422, no. 6933, pp. 746-752, 2003.

[129] P. Chang, M. K. Jacobson, and T. J. Mitchison, "Poly(ADPribose) is required for spindle assembly and structure," Nature, vol. 432, no. 7017, pp. 645-649, 2004.

[130] P. Chang, M. Coughlin, and T. J. Mitchison, “Tankyrase-1 polymerization of poly(ADP-ribose) is required for spindle structure and function," Nature Cell Biology, vol. 7, no. 11, pp. 1133-1139, 2005.

[131] M. Kanai, W. M. Tong, Z. Q. Wang, and M. Miwa, "Haploinsufficiency of poly(ADP-ribose) polymerase-1-mediated poly(ADP-ribosyl)ation for centrosome duplication," Biochemical and Biophysical Research Communications, vol. 359, no. 3, pp. 426-430, 2007.

[132] M. Kanai, M. Uchida, S. Hanai, N. Uematsu, K. Uchida, and M. Miwa, "Poly(ADP-ribose) polymerase localizes to the centrosomes and chromosomes," Biochemical and Biophysical Research Communications, vol. 278, no. 2, pp. 385-389, 2000.

[133] M. Kanai, W. M. Tong, E. Sugihara, Z. Q. Wang, K. Fukasawa, and M. Miwa, "Involvement of poly(ADP-ribose) polymerase 1 and poly(ADP-ribosyl)ation in regulation of centrosome function," Molecular and Cellular Biology, vol. 23, no. 7, pp. 2451-2462, 2003.

[134] A. Saxena, L. H. Wong, P. Kalitsis, E. Earle, L. G. Shaffer, and K. H. A. Choo, "Poly(ADP-ribose) polymerase 2 localizes to mammalian active centromeres and interacts with PARP-1, Cenpa, Cenpb and Bub3, but not Cenpc," Human Molecular Genetics, vol. 11, no. 19, pp. 2319-2329, 2002.

[135] A. Saxena, R. Saffery, L. H. Wong, P. Kalitsis, and K. H. A. Choo, "Centromere proteins Cenpa, Cenpb, and Bub3 interact with poly(ADP-ribose) polymerase-1 protein and are poly(ADP-ribosyl)ated," Journal of Biological Chemistry, vol. 277, no. 30, pp. 26921-26926, 2002.

[136] D. J. Baker, K. B. Jeganathan, J. D. Cameron et al., "BubR1 insufficiency causes early onset of aging-associated phenotypes and infertility in mice," Nature Genetics, vol. 36, no. 7, pp. 744-749, 2004.

[137] D. J. Baker, K. B. Jeganathan, L. Malureanu, C. Perez-Terzic, A. Terzic, and J. M. A. Van Deursen, "Early aging-associated phenotypes in Bub3/Rae1 haploinsufficient mice," Journal of Cell Biology, vol. 172, no. 4, pp. 529-540, 2006.

[138] H. C. Reinhardt and B. Schumacher, "The p53 network: cellular and systemic DNA damage responses in aging and cancer," Trends in Genetics, vol. 28, no. 3, pp. 128-136, 2012.

[139] J. Wesierska-Gadek, C. Ranftler, and G. Schmid, "Physiological ageing: role of p53 and PARP-1 tumor suppressors in the 
regulation of terminal senescence," Journal of Physiology and Pharmacology, vol. 56, supplement 2, pp. 77-88, 2005.

[140] W. M. Tong, H. Ohgaki, H. Huang, C. Granier, P. Kleihues, and Z. Q. Wang, "Null mutation of DNA strand breakbinding molecule poly(ADP-ribose) polymerase causes medulloblastomas in p53-/- mice," American Journal of Pathology, vol. 162, no. 1, pp. 343-352, 2003.

[141] W. M. Tong, Y. G. Yang, W. H. Cao et al., "Poly(ADP-ribose) polymerase-1 plays a role in suppressing mammary tumourigenesis in mice," Oncogene, vol. 26, no. 26, pp. 3857-3867, 2007.

[142] R. Beneke and T. Möröy, "Inhibition of poly(ADP-ribose) polymerase activity accelerates T-cell lymphomagenesis in p53 deficient mice," Oncogene, vol. 20, no. 56, pp. 8136-8141, 2001.

[143] W. M. Tong, M. P. Hande, P. M. Lansdorp, and Z. Q. Wang, "DNA strand break-sensing molecule poly(ADP-ribose) polymerase cooperates with p53 in telomere function, chromosome stability, and tumor suppression," Molecular and Cellular Biology, vol. 21, no. 12, pp. 4046-4054, 2001.

[144] S. R. Kumari, H. Mendoza-Alvarez, and R. Alvarez-Gonzalez, "Functional interactions of $\mathrm{p} 53$ with poly(ADP-ribose) polymerase (PARP) during apoptosis following DNA damage: covalent poly(ADP-ribosyl)ation of $\mathrm{p} 53$ by exogenous PARP and noncovalent binding of p53 to the M(r) 85,000 proteolytic fragment," Cancer Research, vol. 58, no. 22, pp. 50755078, 1998.

[145] M. T. Valenzuela, R. Guerrero, M. I. Núñez et al., "PARP1 modifies the effectiveness of p53-mediated DNA damage response," Oncogene, vol. 21, no. 7, pp. 1108-1116, 2002.

[146] X. Wang, K. Ohnishi, A. Takahashi, and T. Ohnishi, "Poly (ADP-ribosyl)ation is required for p53-dependent signal transduction induced by radiation," Oncogene, vol. 17, no. 22, pp. 2819-2825, 1998.

[147] S. Wieler, J. P. Gagné, H. Vaziri, G. G. Poirier, and S. Benchimol, "Poly(ADP-ribose) polymerase-1 is a positive regulator of the p53-mediated G1 arrest response following ionizing radiation," Journal of Biological Chemistry, vol. 278, no. 21, pp. 18914-18921, 2003.

[148] M. H. Lee, H. Na, E. Kim, H. Lee, and M. Lee, "Poly(ADPribosyl)ation of $\mathrm{p} 53$ induces gene-specific transcriptional repression of MTA1," Oncogene, January 2012.

[149] H. Mendoza-Alvarez and R. Alvarez-Gonzalez, "Regulation of p53 Sequence-specific DNA-binding by Covalent Poly (ADP-ribosyl)ation," Journal of Biological Chemistry, vol. 276, no. 39, pp. 36425-36430, 2001.

[150] C. M. Simbulan-Rosenthal, D. S. Rosenthal, R. Luo et al., "Poly(ADP-ribosyl)ation of $\mathrm{p} 53$ in vitro and in vivo modulates binding to its DNA consensus sequence," Neoplasia, vol. 3, no. 3, pp. 179-188, 2001.

[151] M. Kanai, K. Hanashiro, S. H. Kim et al., "Inhibition of Crm1-p53 interaction and nuclear export of p53 by poly (ADP-ribosyl)ation," Nature Cell Biology, vol. 9, no. 10, pp. 1175-1183, 2007.

[152] K. Grube and A. Bürkle, "Poly(ADP-ribose) polymerase activity in mononuclear leukocytes of 13 mammalian species correlates with species-specific life span," Proceedings of the National Academy of Sciences of the United States of America, vol. 89, no. 24, pp. 11759-11763, 1992.

[153] S. Beneke, A. L. Scherr, V. Ponath, O. Popp, and A. Bürkle, "Enzyme characteristics of recombinant poly(ADPribose) polymerases- 1 of rat and human origin mirror the correlation between cellular poly(ADP-ribosyl)ation capacity and species-specific life span," Mechanisms of Ageing and Development, vol. 131, no. 5, pp. 366-369, 2010.

[154] A. Kunzmann, G. Dedoussis, J. Jajte, M. Malavolta, E. Mocchegiani, and A. Bürkle, "Effect of zinc on cellular poly (ADP-ribosyl)ation capacity," Experimental Gerontology, vol. 43, no. 5, pp. 409-414, 2008.

[155] M. L. Muiras, M. Müller, F. Schächter, and A. Bürkle, "Increased poly(ADP-ribose) polymerase activity in lymphoblastoid cell lines from centenarians," Journal of Molecular Medicine, vol. 76, no. 5, pp. 346-354, 1998.

[156] M. Chevanne, C. Calia, M. Zampieri et al., "Oxidative DNA damage repair and parp 1 and parp 2 expression in EpsteinBarr virus-immortalized B lymphocyte cells from young subjects, old subjects, and centenarians," Rejuvenation Research, vol. 10, no. 2, pp. 191-203, 2007.

[157] S. Shall and G. De Murcia, "Poly(ADP-ribose) polymerase1: what have we learned from the deficient mouse model?" Mutation Research, vol. 460, no. 1, pp. 1-15, 2000.

[158] T. S. Piskunova, M. Yurova, A. Ovsyannikov et al., "Deficiency in poly(ADP-ribose) polymerase-1 (PARP-1) accelerates aging and spontaneous carcinogenesis in mice," Current Gerontology and Geriatrics Research, vol. 2008, p. 754190, 2008.

[159] W. M. Tong, U. Cortes, M. Prakash Hande et al., "Synergistic role of Ku80 and poly(ADP-ribose) polymerase in suppressing chromosomal aberrations and liver cancer formation," Cancer Research, vol. 62, no. 23, pp. 6990-6996, 2002.

[160] T. Nozaki, H. Fujihara, M. Watanabe et al., "Parp-1 deficiency implicated in colon and liver tumorigenesis induced by azoxymethane," Cancer Science, vol. 94, no. 6, pp. 497-500, 2003.

[161] M. Tsutsumi, M. Masutani, T. Nozaki et al., "Increased susceptibility of poly(ADP-ribose) polymerase-1 knockout mice to nitrosamine carcinogenicity," Carcinogenesis, vol. 22, no. 1, pp. 1-3, 2001.

[162] F. Cottet, H. Blanché, P. Verasdonck et al., "New polymorphisms in the human poly(ADP-ribose) polymerase-1 coding sequence: lack of association with longevity or with increased cellular poly(ADP-ribosyl)ation capacity," Journal of Molecular Medicine, vol. 78, no. 8, pp. 431-440, 2000.

[163] K. L. Lockett, M. C. Hall, J. Xu et al., "The ADPRT V762A genetic variant contributes to prostate cancer susceptibility and deficient enzyme function," Cancer Research, vol. 64, no. 17, pp. 6344-6348, 2004.

[164] Q. Zhang, Y. Li, X. Li et al., "PARP-1 Val762Ala polymorphism, CagA $+\mathrm{H}$. pylori infection and risk for gastric cancer in Han Chinese population," Molecular Biology Reports, vol. 36, no. 6, pp. 1461-1467, 2009.

[165] X. Zhang, X. Miao, G. Liang et al., "Polymorphisms in DNA base excision repair genes ADPRT and XRCC1 and risk of lung cancer," Cancer Research, vol. 65, no. 3, pp. 722-726, 2005.

[166] X. G. Wang, Z. Q. Wang, W. M. Tong, and Y. Shen, "PARP1 Val762Ala polymorphism reduces enzymatic activity," Biochemical and Biophysical Research Communications, vol. 354, no. 1, pp. 122-126, 2007.

[167] P. O. Hassa and M. O. Hottiger, "The functional role of poly(ADP-ribose)polymerase 1 as novel coactivator of NF$\kappa \mathrm{B}$ in inflammatory disorders," Cellular and Molecular Life Sciences, vol. 59, no. 9, pp. 1534-1553, 2002.

[168] M. Masutani, H. Suzuki, N. Kamada et al., "Poly(ADPribose) polymerase gene disruption conferred mice resistant to streptozotocin-induced diabetes," Proceedings of the National Academy of Sciences of the United States of America, vol. 96, no. 5, pp. 2301-2304, 1999. 
[169] V. Burkart, Z. Q. Wang, J. Radons et al., "Mice lacking the poly(ADP-ribose) polymerase gene are resistant to pancreatic beta-cell destruction and diabetes development induced by streptozocin," Nature Medicine, vol. 5, no. 3, pp. 314-319, 1999.

[170] A. S. Mandir, S. Przedborski, V. Jackson-Lewis et al., "Poly (ADP-ribose) polymerase activation mediates 1-methyl-4phenyl-1,2,3,6-tetrahydropyridine (MPTP)-induced parkinsonism," Proceedings of the National Academy of Sciences of the United States of America, vol. 96, no. 10, pp. 5774-5779, 1999.

[171] A. A. Pieper, D. J. Brat, D. K. Krug et al., "Poly(ADP-ribose) polymerase-deficient mice are protected from streptozotocin-induced diabetes," Proceedings of the National Academy of Sciences of the United States of America, vol. 96, no. 6, pp. 3059-3064, 1999.

[172] W. L. Kraus, “Transcriptional control by PARP-1: chromatin modulation, enhancer-binding, coregulation, and insulation," Current Opinion in Cell Biology, vol. 20, no. 3, pp. 294 302, 2008.

[173] M. S. Hayden and S. Ghosh, "Shared principles in NF- $\kappa$ B signaling," Cell, vol. 132, no. 3, pp. 344-362, 2008.

[174] A. S. Adler, T. L. A. Kawahara, E. Segal, and H. Y. Chang, "Reversal of aging by NF $\kappa$ B blockade," Cell Cycle, vol. 7, no. 5, pp. 556-559, 2008.

[175] T. L. A. Kawahara, E. Michishita, A. S. Adler et al., "SIRT6 links histone H3 lysine 9 deacetylation to NF- $\kappa$ B-dependent gene expression and organismal life span," Cell, vol. 136, no. 1, pp. 62-74, 2009.

[176] A. S. Adler, S. Sinha, T. L. A. Kawahara, J. Y. Zhang, E. Segal, and H. Y. Chang, "Motif module map reveals enforcement of aging by continual NF- $\kappa \mathrm{B}$ activity," Genes and Development, vol. 21, no. 24, pp. 3244-3257, 2007.

[177] A. Moskalev and M. Shaposhnikov, "Pharmacological inhibition of NF- $\kappa$ B prolongs lifespan of Drosophila melanogaster," Aging, vol. 3, no. 4, pp. 391-394, 2011.

[178] E. Rovillain, L. Mansfield, C. Caetano et al., "Activation of nuclear factor- $\kappa$ B signalling promotes cellular senescence," Oncogene, vol. 30, no. 20, pp. 2356-2366, 2011.

[179] J. Wang, N. K. Jacob, K. J. Ladner et al., "RelA/p65 functions to maintain cellular senescence by regulating genomic stability and DNA repair," EMBO Reports, vol. 10, no. 11, pp. 1272$1278,2009$.

[180] J. S. Tilstra, C. L. Clauson, L. J. Niedernhofer, and P. D. Robbins, "NF- $\kappa \mathrm{B}$ in aging and disease," Aging and Disease, vol. 2, no. 6, pp. 449-465, 2011.

[181] F. J. Oliver, J. Ménissier-de Murcia, C. Nacci et al., "Resistance to endotoxic shock as a consequence of defective NF$\kappa \mathrm{B}$ activation in poly (ADP-ribose) polymerase-1 deficient mice," EMBO Journal, vol. 18, no. 16, pp. 4446-4454, 1999.

[182] P. O. Hassa and M. O. Hottiger, "A role of poly (ADP-Ribose) polymerase in NF- $\kappa$ B transcriptional activation," Biological Chemistry, vol. 380, no. 7-8, pp. 953-959, 1999.

[183] P. O. Hassa, M. Covic, S. Hasan, R. Imhof, and M. O. Hottiger, "The enzymatic and DNA binding activity of PARP1 are not required for NF- $\kappa$ B coactivator function," Journal of Biological Chemistry, vol. 276, no. 49, pp. 45588-45597, 2001.

[184] M. Altmeyer and M. O. Hottiger, "Poly(ADP-ribose) polymerase 1 at the crossroad of metabolic stress and inflammation in aging," Aging, vol. 1, no. 5, pp. 458-469, 2009.

[185] M. Stilmann, M. Hinz, S. C. Arslan, A. Zimmer, V. Schreiber, and C. Scheidereit, "A nuclear poly(ADP-Ribose)-dependent signalosome confers DNA damage-induced I $\kappa$ B kinase activation," Molecular Cell, vol. 36, no. 3, pp. 365-378, 2009.
[186] M. Ohanna, S. Giuliano, C. Bonet et al., "Senescent cells develop a parp-1 and nuclear factor- $\kappa \mathrm{B}$-associated secretome (PNAS)," Genes and Development, vol. 25, no. 12, pp. 12451261, 2011.

[187] R. S. Hotchkiss, A. Strasser, J. E. McDunn, and P. E. Swanson, "Cell death," New England Journal of Medicine, vol. 361, no. 16, pp. 1570-1583, 2009.

[188] L. E. Broker, F. A. E. Kruyt, and G. Giaccone, "Cell death independent of caspases: a review," Clinical Cancer Research, vol. 11, no. 9, pp. 3155-3162, 2005.

[189] N. A. Berger, J. L. Sims, D. M. Catino, and S. J. Berger, "Poly(ADP-ribose) polymerase mediates the suicide response to massive DNA damage: studies in normal and DNA-repair defective cells," Princess Takamatsu symposia, vol. 13, pp. 219-226, 1983.

[190] C. Negri, M. Donzelli, R. Bernardi, L. Rossi, A. Bürkle, and A. I. Scovassi, "Multiparametric staining to identify apoptotic human cells," Experimental Cell Research, vol. 234, no. 1, pp. 174-177, 1997.

[191] M. Tewari, L. T. Quan, K. O’Rourke et al., "Yama/CPP32 $\beta$, a mammalian homolog of CED-3, is a CrmA-inhibitable protease that cleaves the death substrate poly(ADP-ribose) polymerase," Cell, vol. 81, no. 5, pp. 801-809, 1995.

[192] Y. A. Lazebnik, S. H. Kaufmann, S. Desnoyers, G. G. Poirier, and W. C. Earnshaw, "Cleavage of poly(ADP-ribose) polymerase by a proteinase with properties like ICE," Nature, vol. 371, no. 6495, pp. 346-347, 1994.

[193] M. Germain, E. B. Affar, D. D’Amours, V. M. Dixit, G. S. Salvesen, and G. G. Poirier, "Cleavage of automodified poly(ADP-ribose) polymerase during apoptosis. Evidence for involvement of caspase-7," Journal of Biological Chemistry, vol. 274, no. 40, pp. 28379-28384, 1999.

[194] S. W. Yu, H. Wang, M. F. Poitras et al., "Mediation of poty(ADP-ribose) polymerase-1-dependent cell death by apoptosis-inducing factor," Science, vol. 297, no. 5579, pp. 259-263, 2002.

[195] O. Cohausz, C. Blenn, M. Malanga, and F. R. Althaus, "The roles of poly(ADP-ribose)-metabolizing enzymes in alkylation-induced cell death," Cellular and Molecular Life Sciences, vol. 65, no. 4, pp. 644-655, 2008.

[196] Y. Wang, N. S. Kim, J. F. Haince et al., "Poly(ADP-ribose) (PAR) binding to apoptosis-inducing factor is critical for PAR polymerase-1-dependent cell death (parthanatos)," Science Signaling, vol. 4, no. 167, p. ra20, 2011.

[197] S.-W. Yu, S. A. Andrabi, H. Wang et al., "Apoptosis-inducing factor mediates poly(ADP-ribose) (PAR) polymer-induced cell death," Proceedings of the National Academy of Sciences of the United States of America, vol. 103, no. 48, pp. 1831418319, 2006.

[198] S. A. Andrabi, S. K. No, S.-W. Yu et al., "Poly(ADP-ribose) (PAR) polymer is a signal," Proceedings of the National Academy of Sciences of the United States of America, vol. 103, no. 48, pp. 18308-18313, 2006.

[199] R. Aguilar-Quesada, J. A. Muñoz-Gámez, D. Martín-Oliva et al., "Modulation of transcription by PARP-1: consequences in carcinogenesis and inflammation," Current Medicinal Chemistry, vol. 14, no. 11, pp. 1179-1187, 2007.

[200] T. Radovits, L. Seres, D. Gero et al., "Single dose treatment with PARP-inhibitor INO-1001 improves aging-associated cardiac and vascular dysfunction," Experimental Gerontology, vol. 42, no. 7, pp. 676-685, 2007.

[201] T. Von Lukowicz, P. O. Hassa, C. Lohmann et al., "PARP1 is required for adhesion molecule expression in atherogenesis," Cardiovascular Research, vol. 78, no. 1, pp. 158-166, 2008. 
[202] R. El Ramy, N. Magroun, N. Messadecq et al., "Functional interplay between parp-1 and SirT1 in genome integrity and chromatin-based processes," Cellular and Molecular Life Sciences, vol. 66, no. 19, pp. 3219-3234, 2009.

[203] R. H. Houtkooper, E. Pirinen, and J. Auwerx, "Sirtuins as regulators of metabolism and healthspan," Nature Reviews Molecular Cell Biology, vol. 13, no. 4, pp. 225-238, 2012.

[204] R. Firestein, G. Blander, S. Michan et al., "The SIRT1 deacetylase suppresses intestinal tumorigenesis and colon cancer growth," PLoS ONE, vol. 3, no. 4, Article ID e2020, 2008.

[205] A. S. Banks, N. Kon, C. Knight et al., "SirT1 gain of function increases energy efficiency and prevents diabetes in mice," Cell Metabolism, vol. 8, no. 4, pp. 333-341, 2008.

[206] L. Bordone, D. Cohen, A. Robinson et al., "SIRT1 transgenic mice show phenotypes resembling calorie restriction," Aging Cell, vol. 6, no. 6, pp. 759-767, 2007.

[207] P. T. Pfluger, D. Herranz, S. Velasco-Miguel, M. Serrano, and M. H. Tschöp, "Sirt1 protects against high-fat diet-induced metabolic damage," Proceedings of the National Academy of Sciences of the United States of America, vol. 105, no. 28, pp. 9793-9798, 2008.

[208] K. A. Moynihan, A. A. Grimm, M. M. Plueger et al., "Increased dosage of mammalian Sir2 in pancreatic $\beta$ cells enhances glucose-stimulated insulin secretion in mice," Cell Metabolism, vol. 2, no. 2, pp. 105-117, 2005.

[209] P. Bai, C. Cantó, H. Oudart et al., "PARP-1 inhibition increases mitochondrial metabolism through SIRT1 activation," Cell Metabolism, vol. 13, no. 4, pp. 461-468, 2011.

[210] A. Mangerich, N. Herbach, B. Hanf et al., "Inflammatory and age-related pathologies in mice with ectopic expression of human PARP-1," Mechanisms of Ageing and Development, vol. 131, no. 6, pp. 389-404, 2010.

[211] R. Zarychanski and D. S. Houston, "Clinical paradigms: anemia of chronic disease: a harmful disorder or an adaptive, beneficial response?" CMAJ, vol. 179, no. 4, pp. 333-337, 2008.

[212] G. Weiss and L. T. Goodnough, "Anemia of chronic disease," New England Journal of Medicine, vol. 352, no. 10, pp. 10111059, 2005.

[213] A. M. Westbrook, B. Wei, J. Braun, and R. H. Schiestl, "Intestinal inflammation induces genotoxicity to extraintestinal tissues and cell types in mice," International Journal of Cancer, vol. 7, no. 6, 2011.

[214] T. B. L. Kirkwood, "Understanding the odd science of aging," Cell, vol. 120, no. 4, pp. 437-447, 2005.

[215] S. Gerondakis, R. Grumont, R. Gugasyan et al., "Unravelling the complexities of the NF- $\kappa \mathrm{B}$ signalling pathway using mouse knockout and transgenic models," Oncogene, vol. 25, no. 51, pp. 6781-6799, 2006. 


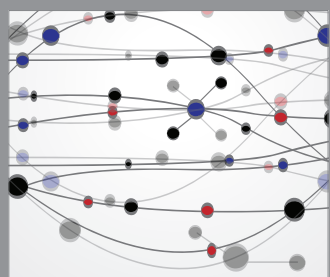

The Scientific World Journal
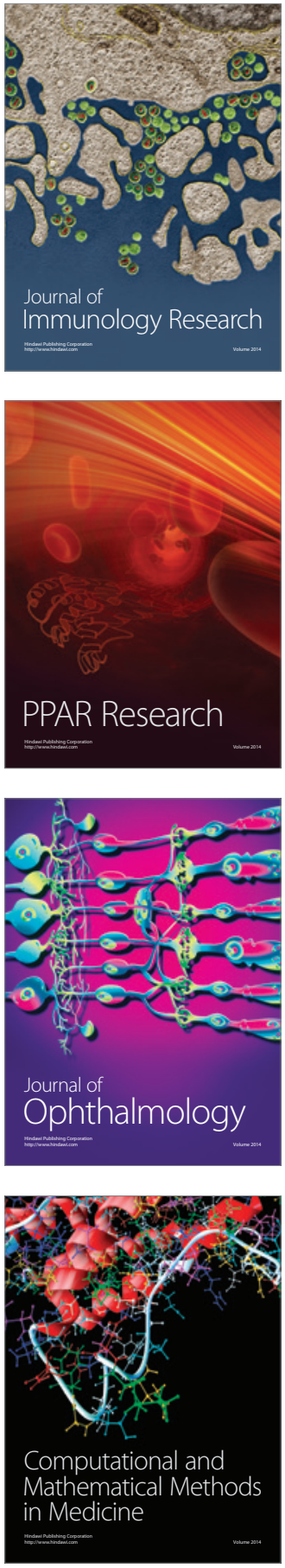

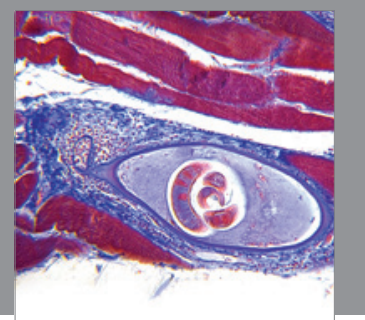

Gastroenterology

Research and Practice
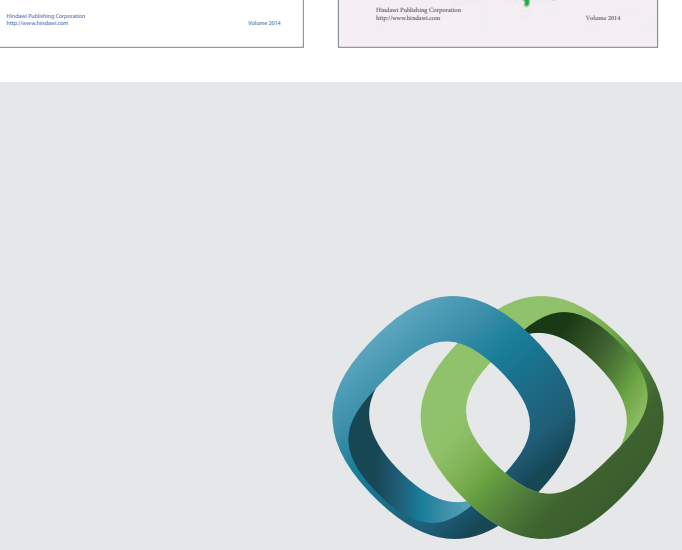

\section{Hindawi}

Submit your manuscripts at

http://www.hindawi.com
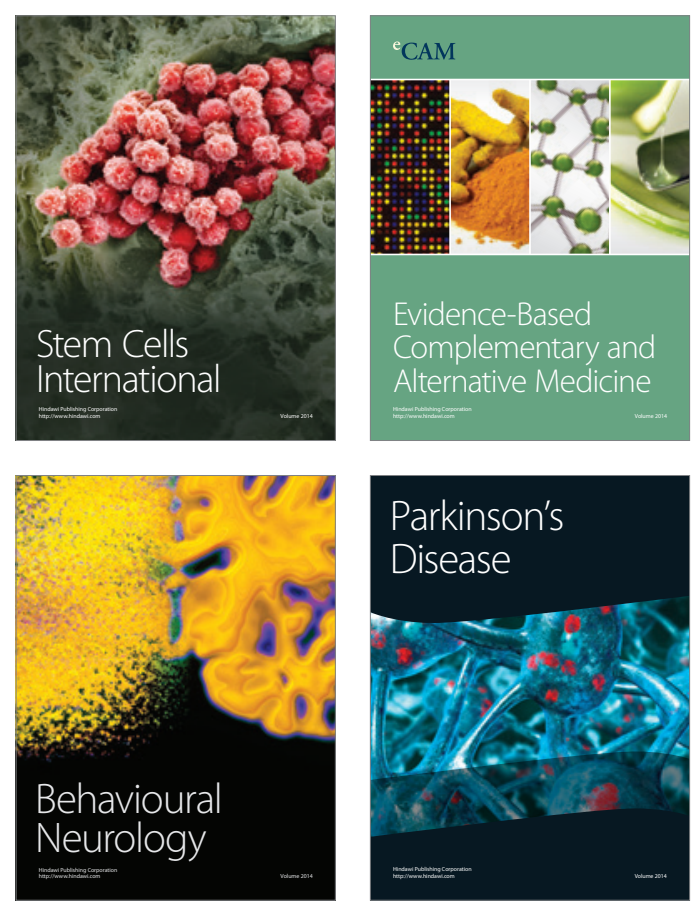

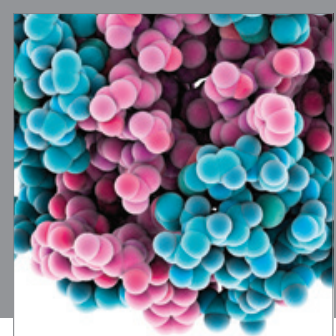

Journal of
Diabetes Research

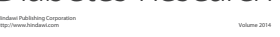

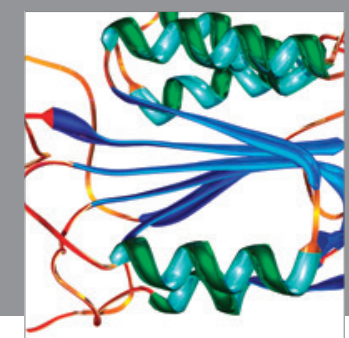

Disease Markers
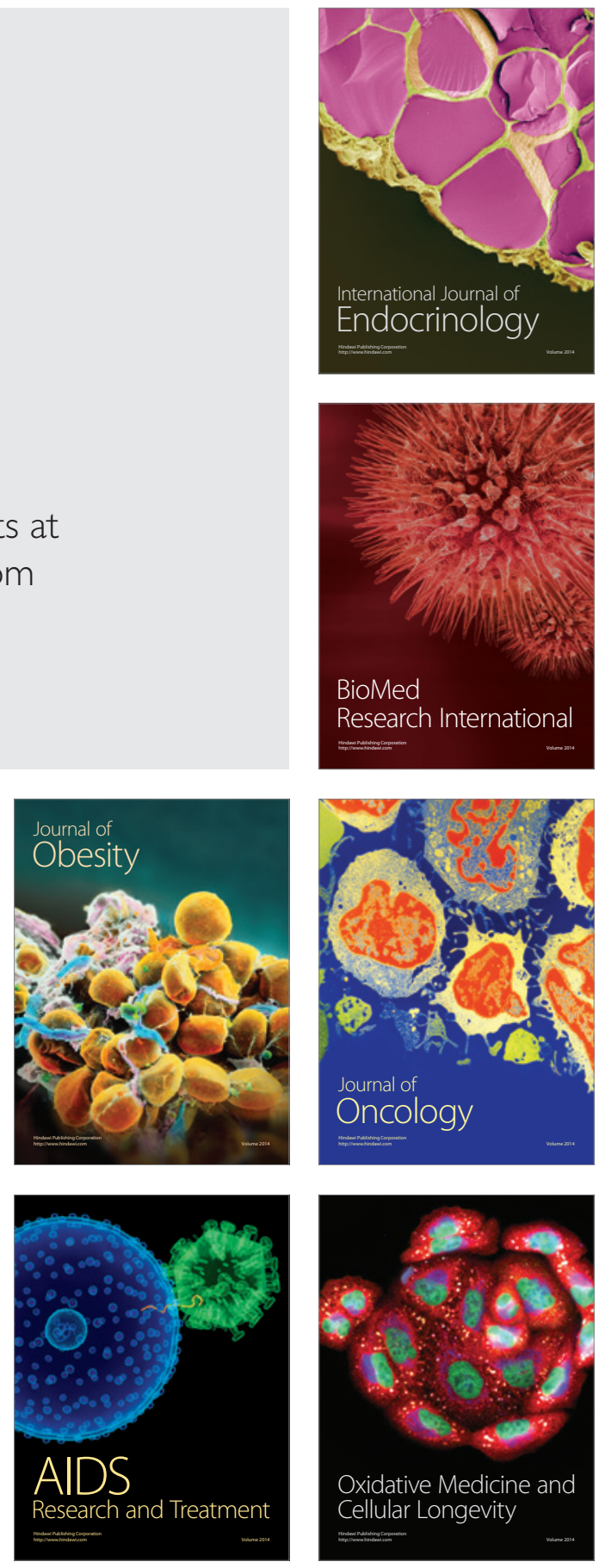